\title{
Statement on malignant mesothelioma in the United Kingdom
}

\author{
British Thoracic Society Standards of Care Committee
}

\section{Introduction}

Malignant mesothelioma is one of the more difficult diseases that doctors, patients, and families have to face. It is almost always caused by inhalation of asbestos fibre many years before presentation. Diagnosis can be difficult, there is little hope of a cure, and the disease has the potential for extremely unpleasant symptoms.

The incidence is increasing rapidly and the position of mesothelioma in the league table of cancer related deaths is rising. However, few doctors have managed sufficient numbers of patients to have acquired comprehensive clinical experience of the disease. Furthermore, the relative rarity of the condition and lack of extensive research mean that clinicians do not have reliable evidence on which to base their practice.

The British Thoracic Society (BTS) Standards of Care Committee was asked by the National Health Executive in England to consider what could be done to improve management in the light of the increasing incidence. A Working Party was established, comprising clinicians with interest and experience of the condition, with a view to compiling guidelines to assist in the management of mesothelioma (both pleural and peritoneal) in the UK. The
Working Party was supplemented by co-opted specialists. These included radiologists, pathologists, and oncologists and full details are given in Appendix 1.

The draft was reviewed by the whole membership of the BTS from whom extensive comments were gratefully received. The document was also sent to expert groups and representatives of patients and the government for opinion, and the statement is the result of this consultation process. It is compiled primarily for clinicians who may be involved in the care of patients with mesothelioma, and is based on literature searches and reviews by members of the Working Party responsible for particular sections. However, it is not strictly evidence based as we did not attempt to review comprehensively all the epidemiological, pathology and medicolegal papers and also because, in many aspects of the subject, there are insufficient randomised trials upon which to base guidelines so we have not used this word in the final document. The Working Party recognises that many aspects of mesothelioma are currently subject to debate and variations in practice. Thus, the statement is offered for guidance and is not an attempt dogmatically to dictate management.
Dr J Wiggins, Wexham Park Hospital, Wexham, Slough, Berkshire SL2 4HL, UK 


\section{Summary of key points}

Pleural mesothelioma

PRESENTATION AND NATURAL HISTORY

- Mesothelioma should be considered in any patient with either pleural fluid or pleural thickening, especially if chest pain is present.

- Mesothelioma may occasionally present with persistent unexplained chest pain and a normal chest radiograph.

- Symptomatic metastatic disease is unusual at presentation.

- The disease is inexorably progressive except in the few patients who have undergone curative surgery.

PROGNOSIS

- Median survival is poor, varying from 8 to 14 months in different studies, similar to other types of lung cancer.

- Epithelioid tumours have a better than average prognosis.

DIAGNOSIS

- The importance of a detailed occupational history cannot be overemphasised.

- Any patient in whom mesothelioma is suspected should be promptly referred to a respiratory physician for further assessment.

- Pathological confirmation of the diagnosis is recommended, unless the patient is frail or has extremely advanced disease.

- Negative pleural biopsy and cytology results do not exclude mesothelioma and should lead to further investigation.

- CT scanning plays a key role in the diagnosis of mesothelioma.

Diagnostic imaging

- CT scanning should be performed on all patients with undiagnosed pleural exudates.

- Pleural plaques are indicators of asbestos exposure but are absent in many proven cases of mesothelioma attributable to asbestos fibre.

- Demonstration of chest wall invasion by either CT scanning or MRI is highly suggestive of malignant rather than benign pleural disease.

Pathological diagnosis

- Pleural fluid cytology and histology of blind biopsy specimens have low diagnostic yield for mesothelioma but are important initial steps in differential diagnosis.

- Ultrasound and CT guided biopsy and thoracoscopic and surgical biopsy techniques should be used to increase the likelihood of accurate diagnosis.

- Pathologists should attempt to specify the histological type of mesothelioma.

- A selection of special stains should be used to help differentiation of mesothelioma and pleural adenocarcinoma.

TREATMENT STRATEGY

- Staging is essential for correct selection of patients for surgery.

- Staging provides important prognostic information.

- Staging should be undertaken before clinical trials.

RADICAL SURGERY

- There are no randomised control trials to establish the role of radical surgery.

- Radical surgery should only be considered when there is a positive diagnosis of epithelioid mesothelioma.

- Surgery should only be performed in centres where there is an interest and experience in performing extrapleuropneumonectomies.

- The limited evidence available has reported surgical results only as part of a multimodality treatment strategy.

MANAGEMENT OF PLEURAL EFFUSIONS

- Talc pleurodesis is probably the treatment of choice for the control of pleural fluid.

- VATS pleurectomy is an effective treatment to control pleural fluid in mesothelioma and is much safer than open pleurectomy and decortication.

- The value of pleuroperitoneal shunts remains uncertain.

RADIOTHERAPY

- Prophylactic radiotherapy reduces chest wall implantation following invasive procedures.

- Palliative radiotherapy provides pain relief in about half of all patients.

- Palpable masses respond to radiotherapy in about half of all patients.

- Breathlessness and superior vena caval obstruction rarely respond to radiotherapy.

CHEMOTHERAPY

- All patients with mesothelioma should have the opportunity to discuss the pros and cons of chemotherapy with either an oncologist or respiratory specialist.

- There are no published randomised trials comparing either survival or symptom control in patients treated with chemotherapy or best supportive care. 
- Chemotherapy, where used, should be given as part of a clinical trial.

- Clinicians should be encouraged to enter patients into suitable trials.

NEW APPROACHES TO TREATMENT

- Gene therapy, photodynamic therapy, and immunotherapy do not yet have an established role.

PALLIATIVE CARE

- Most patients need symptom palliation from the time of diagnosis onwards.

- Palliative care should aim to provide relief from pain and other physical symptoms and to respond to emotional, psychological, social and spiritual needs.

General management

- Patients with mesothelioma should be under the care of a specialist.

- The specialist should ensure that the diagnosis is communicated skilfully and sympathetically with a clear picture of the disease and the management plan.

- This information should be communicated immediately to the general practitioner.

- Written information about the disease and relevant organisations should be available to a patient and family.

- An appropriately trained specialist nurse should be involved from the outset to support the care of the patient and liaise between hospital services, primary care, and specialist palliative care services.

- The general practitioner should be reminded that all deaths have to be reported to the Coroner (in Scotland the Procurator Fiscal); a post mortem is usually required.

Symptom control

- Early involvement of a pain relief service is often needed.

- Breathlessness is often multifactorial and a variety of approaches may be necessary for palliation.

Peritoneal mesothelioma

- Peritoneal mesothelioma is related to asbestos exposure but is less common than pleural mesothelioma.

- The outlook is poor and no treatment has been shown to alter prognosis.

\section{Epidemiology}

The incidence of mesothelioma has been rapidly increasing since its first description in 1960. It is expected to increase over the next 20 years from the present total of 1300 to more than 3000 cases per year in Britain. ${ }^{1}$ For the worst affected cohorts - that is, men born in the $1940 \mathrm{~s}$-mesothelioma may account for around $1 \%$ of all deaths.

Asbestos fibres are the cause of most cases. In subjects without exposure to asbestos spontaneous cases are rare, ${ }^{2}$ accounting for about one in 10000 deaths. ${ }^{3}$ However, mesothelioma can be induced by non-asbestos fibres such as erionite found in rocks in certain areas of Turkey. Other contributory causes have been suggested such as the Simian virus 40 (SV 40), although the evidence is weak. Mesothelioma also results from non-industrial environmental contact with asbestos fibres and paraoccupational exposure occurs-for example, women who have laundered their husband's overalls. The most recent well documented series suggests that a history of occupational asbestos exposure can be obtained in about $90 \%$ of cases in the UK. ${ }^{4}$ In subjects heavily exposed to asbestos early in their working life, more than one in 10 may die of mesothelioma. ${ }^{5}$ Epidemiological trends throughout Europe are consistent.

There is no evidence for a threshold dose of asbestos below which there is no risk. However, the risk at low levels of exposure is small. There is no significant risk from asbestos in place in buildings provided it is well sealed and not releasing dust. ${ }^{6}$ All types of asbestos can cause mesothelioma. Amphibole fibres, of which the commercially important examples are crocidolite (blue asbestos) and amosite (brown asbes- tos), are the more potent causes. There has been much debate about the aetiological role of chrysotile (white asbestos). However, a recent WHO review has concluded that chrysotile asbestos does, indeed, pose an increased risk of mesothelioma in a dose dependent manner ${ }^{7}$; this form of asbestos is also the most widely used. There is no evidence that mesothelioma can be caused by either fibreglass or other building materials, cigarette smoking, or intrapleural talc.

The average latent interval between first exposure to asbestos and death is very long. One recent series suggests a mean of 41 years (range 15-67). ${ }^{4}$ Cases appearing less than 15 years after exposure are rare. ${ }^{6}$ The long latent interval and the fact that peak imports of asbestos into the UK occurred in the 1970s account for the currently increasing incidence.

Many thousands of workers have been exposed to asbestos fibre and have heard about the potential dangers, although only a very small proportion will develop life threatening disease as a result of asbestos exposure. These workers have justifiable anxiety about their future and may seek reassurance from the medical profession with routine chest radiographs. Although often requested by patients, annual radiographs of previously exposed individuals cannot be recommended. However, the Control of Asbestos at Work regulations state that workers currently exposed to asbestos above a certain level should be placed under adequate medical surveillance including "a specific examination of the chest" at intervals of less than 2 years; this may include a chest radiograph. 
Pleural mesothelioma

PRESENTATION AND NATURAL HISTORY ${ }^{8} 9$

The typical patient presents with either chest pain or dyspnoea, or both. The chest pain is usually dull, diffuse, and characteristically worsens during the course of the illness; occasionally it is pleuritic. The pain may be described as heaviness or aching in the shoulder, arm, chest wall, and upper abdomen.

The pain sometimes has neuropathic components because of entrapment of intercostal thoracic, autonomic, or brachial plexus nerves. Occasional patients are encountered who present with persistent chest wall pain with clear chest radiographs, but develop either pleural masses or effusions during follow up in the subsequent months.

Dyspnoea is usually caused in the early stages by a pleural effusion, but later may be due to the restrictive effects of pleural thickening. A chest wall mass, weight loss, abdominal pain, and ascites (due to peritoneal involvement) are less common presentations. Finger clubbing occurs more commonly in mesothelioma than in other forms of asbestos related pleural disease. ${ }^{10}$ Profuse sweating may occur.

Occasionally the diagnosis is suspected following a routine chest radiograph. Pleural thickening or a mass may be visible on the chest radiograph after drainage of a presenting effusion and may prompt consideration of the diagnosis, as may the finding of other manifestations of asbestos exposure such as pleural plaques. Bilateral disease occurs rarely at presentation but is not uncommon in the terminal phases.

Unlike carcinoma of the bronchus, cervical adenopathy at presentation, haemoptysis, and symptoms due to distal metastases are unusual. The disease is more likely to progress by local extension than haematogenous spread. Direct involvement of mediastinal structures is common, but hoarseness and superior vena caval obstruction only rarely cause major symptoms and dysphagia, if it occurs, tends to be a pre-terminal event.

Sometimes patients present with acute pleuritic chest pain and a small effusion but initial investigations may fail to give a diagnosis. The patient may then remain symptom free for many months until recurrence of the fluid or the development of chest pain leads to further investigation and diagnosis.

Physical signs depend on the type of disease involvement and include signs of pleural thickening and effusion together with restriction of expansion of the hemithorax. Pericardial involvement is not uncommon and results in symptoms associated with tamponade. Weight loss may be prominent as the disease progresses and the patient may be in pain and breathless. Some patients have periods of

Table 1 Histological type of pleural mesothelioma and survival

\begin{tabular}{llllll}
\hline \multirow{5}{*}{ No of cases } & \multicolumn{3}{l}{ Median survival (months) } & \\
\cline { 2 - 5 } & All types & Epithelioid & Sarcomatoid & Mixed or biphasic & Source \\
\hline 248 & 14.0 & 16.2 & 10.1 & 14.7 & Yates et al ${ }^{4}$ \\
153 & 10 & 11 & 5 & 10 & Hillerdahl \\
83 & 8.1 & 8.4 & 6.9 & 6.3 & ${\text { Van Gelder } \text { et }^{9} l^{12}}^{2}$ \\
\hline
\end{tabular}

apparent stability while others have relentless, rapid deterioration.

\section{Key points}

- Mesothelioma should be considered in any patient with either pleural fluid or pleural thickening, especially if chest pain is present.

- Mesothelioma may occasionally present with persistent unexplained chest pain and a normal chest radiograph.

- Symptomatic metastatic disease is unusual at presentation.

- The disease is inexorably progressive except in the few patients who have undergone curative surgery.

\section{PROGNOSIS}

Several studies have reported survival data, some measuring survival from date of onset of symptoms and others from date of definite diagnosis. A study of asbestos insulation workers in the United States showed that, among 141 cases of pleural mesothelioma, $36 \%$ died within 6 months, 64\% within 12 months, and 94\% within 24 months of the onset of symptoms. Of 244 cases of peritoneal mesothelioma, 55\% died within 6 months, $88 \%$ within 12 months, and $98 \%$ within 24 months of the onset of symptoms. In this series the median survival for pleural mesothelioma from onset of symptoms was 10 months and from diagnosis 5 months. ${ }^{11}$

There are prognostic factors which allow some refinement of prediction of life expectancy. Sarcomatoid, mixed and/or biphasic subtypes, more advanced stage of disease, and older age are significant independent adverse prognostic factors (table 1$).^{12}$

The minority who survive for more than 3 years are almost exclusively from the epithelioid group. ${ }^{9}{ }^{13}$ Contrary to frequently expressed belief, distant metastases occur commonly, although they are usually late and seldom cause problems. Yates et $a l^{4}$ reported their presence in more than $50 \%$ of cases at necroscopic examination, and with similar frequency in all histological types, although Law et $a l^{13}$ found them more commonly in the sarcomatoid variety.

\section{Key points}

- Median survival is poor, varying from 8 to 14 months in different studies, similar to other types of lung cancer.

- Epithelioid tumours have a better than average prognosis.

\section{DIAGNOSIS}

\section{Diagnostic strategy}

The first point to emphasise is the importance of the history, particularly occupational aspects. A detailed occupational history should alert the clinician to the possibility of mesothelioma as a cause of the patient's symptoms. Obtaining an accurate occupational history at the first consultation may have medicolegal importance since it may carry more weight than a history which is elicited after a diagnosis of mesothelioma has been made. A detailed history will include identification of employer and dates of employment, 
together with enquiry about direct and indirect exposure. An accompanying environmental history including questions about employment of parents may be important where no clearcut exposure can be identified. It is important to obtain this history promptly because such details may not be possible to elicit as the patient's condition deteriorates.

A history of direct asbestos exposure may not be obvious. Many cases may occur in patients working in occupations not traditionally recognised as being associated with asbestos exposure, particularly the construction industry. It is recommended that prompt referral to a respiratory physician should occur for any patient in whom early assessment raises the possibility of mesothelioma.

A diagnostic strategy algorithm, based on the clinical presentation which has raised the possibility, is shown in fig 1 . The algorithm emphasises the key role of computed tomographic (CT) scanning and the techniques available to confirm the diagnosis. In a small proportion of patients the diagnosis may not be made even after thoracic surgery. In such individuals clinical follow up may clarify the situation. Benign disease is likely to remain stable while, in patients with mesothelioma, follow up radiology will reveal a progressive pleural mass. If thoracoscopy fails or is not technically possible, open pleural biopsy may ultimately be needed.

In most cases it is preferable to obtain pathological confirmation and the clinician should be aware that negative pleural biopsy and pleural fluid cytological results do not exclude mesothelioma and should lead to further investigation. However, if the diagnosis is reasonably certain on the basis of typical clinical and radiological features, it is appropriate to accept it without taking biopsy specimens in a frail patient or in those in whom there is some contraindication to biopsy techniques.

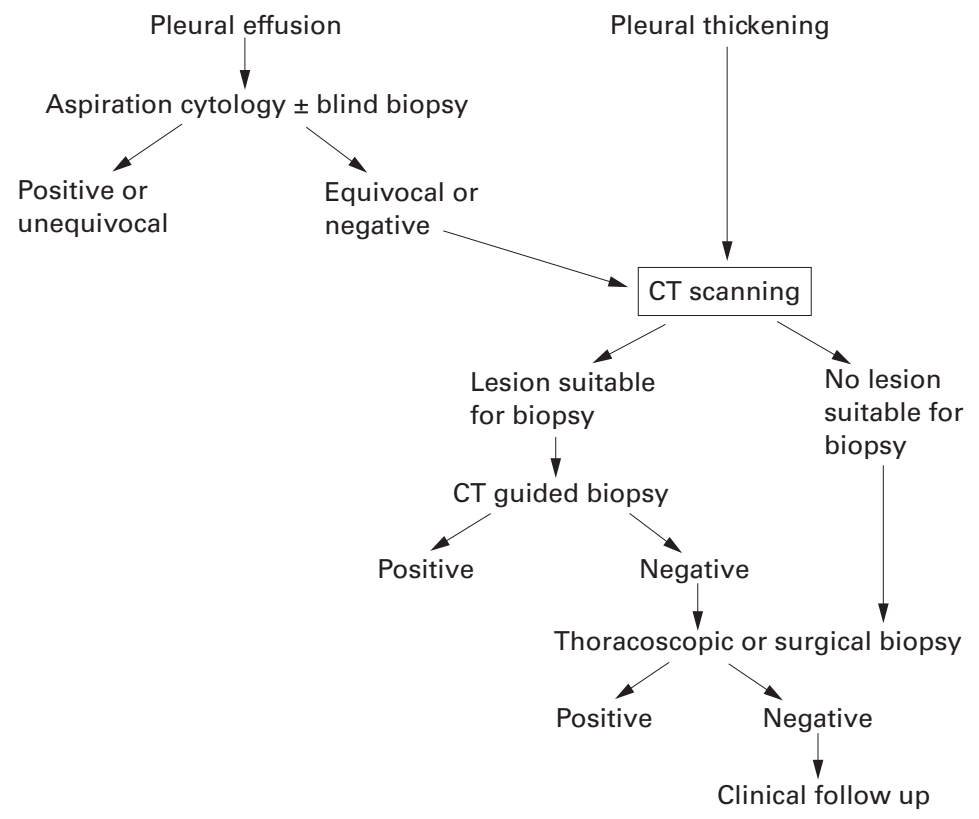

Figure 1 Diagnostic strategy for suspected pleural mesothelioma.
The initial approach to diagnosis depends on the presenting feature. For instance, chest wall pain, unilateral pleural thickening, and undiagnosed pleural effusion all raise the possibility of mesothelioma but are investigated in different ways.

Incorrect diagnosis of mesothelioma leads to missed opportunities for treatment of a disease more responsive to treatment. Furthermore, an erroneous diagnosis of an incurable malignant disease when, in fact, the patient has benign asbestos related pleural thickening may cause unnecessary distress and may prompt irreversible decisions-for example, about employment-before time disproves the diagnosis. Although some authors state that pathological confirmation is not necessary for the prescribed disease of mesothelioma to be diagnosed, in practice lack of confirmation may make it more difficult for the patient to obtain disablement benefits from the Benefits Agency and damages at common law. If a patient is to be included in a clinical trial of treatment, pathological confirmation of the diagnosis is essential.

\section{Key points}

- The importance of a detailed occupational history cannot be overemphasised.

- Any patient in whom mesothelioma is suspected should be promptly referred to a respiratory physician for further assessment.

- Pathological confirmation of the diagnosis is recommended, unless the patient is frail or has extremely advanced disease.

- Negative pleural biopsy and cytological results do not exclude mesothelioma and should lead to further investigation.

- CT scanning plays a key role in the diagnosis of mesothelioma.

Diagnostic imaging

Imaging at presentation - Mesothelioma is usually suspected because of pleural opacification detected on a standard plain chest radiograph. Lateral and plain decubitus views may aid initial assessment. Ultrasound and CT scans may be helpful at presentation, particularly in the differentiation between fluid and solid pleural thickening. CT scanning is also very useful in demonstrating a solid component in association with apparently simple effusions and should be undertaken in all patients with undiagnosed pleural disease. ${ }^{14}$

Frequently, the radiological changes may be associated with pleural plaques from exposure to asbestos, but there are many patients in whom coincidental pleural plaques are not found. A nodular or irregular pleural shadow or pleural thickening extending onto the mediastinal surfaces are pointers to mesothelioma.

Imaging in differential diagnosis - In practice, the main differential diagnosis is between benign pleural thickening and adenocarcinoma involving the pleura. Occasionally empyema, fibrothorax, and apparently idiopathic pleural exudates may cause confusion. Benign pleural 
thickening can sometimes be distinguished from mesothelioma on the CT scan by the presence of a fat line between the pleural thickening and the chest wall. Absence of this line raises the likelihood that the abnormality under assessment is malignant.

Invasion of the chest wall demonstrated by either CT scanning or magnetic resonance imaging (MRI) suggests a malignant lesion as does spread to the mediastinum or the presence of mediastinal lymph nodes. However, it should be remembered that infections such as actinomycosis and tuberculosis can occasionally invade soft tissues.

Imaging of the pleura after drainage of pleural fluid may also provide useful information but radiology can neither make a firm diagnosis of mesothelioma nor reliably distinguish the disease from other forms of malignancy.

Imaging in management-CT scanning can be used to assist diagnosis by a guiding percutaneous needle biopsy. MRI may be of value in determining local spread of tumour, particularly where there is a suspicion about chest wall invasion and assessment of disease in specific areas such as lung apex, diaphragm, heart, and spine. ${ }^{15}$ However, CT and MRI scans provide similar information about resectability in most cases. Sensitivity for detection of involvement of the diaphragm and chest wall is high for both techniques, and both are valuable in appropriate patients when planning radiotherapy and surgery. ${ }^{16}{ }^{17}$ CT scanning is likely to be the initial study for determining resectability in most cases because it is more widely available. Important complementary information is occasionally obtained by MRI in difficult cases because of its ability to provide different views of the pleura. ${ }^{18}$

Routine clinical follow up is usually undertaken with plain radiographs. CT scanning is not generally necessary but may be helpful either when the diagnosis has not been firmly established after initial work up or for assessing a patient's response to chemotherapy.

\section{Key points}

- CT scanning should be performed on all patients with undiagnosed pleural exudates.

- Pleural plaques are indicators of asbestos exposure but are absent in many proven cases of mesothelioma attributable to asbestos fibre.

- Demonstration of chest wall invasion by either CT scanning or MRI is highly

Table 2 Differentiation of epithelioid mesothelioma from adenocarcinoma

\begin{tabular}{|c|c|}
\hline Epithelioid mesothelioma & Adenocarcinoma \\
\hline $\begin{array}{l}\text { Cytoplasm contains glycogen but no diastase } \\
\text { resistant PAS positive material }\end{array}$ & $\begin{array}{l}\text { Glycogen content is small. May contain } \\
\text { diastase resistant PAS positive mucin }\end{array}$ \\
\hline $\begin{array}{l}\text { Alcian blue positive hyaluronic acid in glands } \\
\text { on tumour cell surface }\end{array}$ & No hyaluronic acid within or on tumour cells \\
\hline CEA, Leu $M_{1}$, Ber Ep4, and AUA1 negative & CEA, Leu $M_{1}$, Ber Ep4, and AUA1 positive \\
\hline $\begin{array}{l}\text { Calretinin (positive nuclear staining } \star \text { ), } \\
\text { cytokeratin } 5 / 6 \text { and thrombomodulin } \\
\text { positive }\end{array}$ & $\begin{array}{l}\text { Calretinin (negative nuclear staining }{ }^{\star} \text { ), } \\
\text { cytokeratin } 5 / 6 \text { and thrombomodulin negative }\end{array}$ \\
\hline
\end{tabular}

${ }^{\star}$ Calretinin stains the cytoplasm of both mesothelioma and adenocarcinoma. suggestive of malignant rather than benign pleural disease.

\section{Pathological diagnosis}

Routine cytological examination of pleural fluid has a sensitivity of only $32 \%$ in the diagnosis of mesothelioma, ${ }^{19}$ although immunocytochemistry may assist in distinguishing mesothelioma from adenocarcinoma and from reactive mesothelial cells.

Samples for histological analysis are more useful. It is important that the pathologist is provided with full thickness biopsy specimens since superficial tissue may include only reactive change associated with the malignant process. Blind percutaneous needle biopsy specimens taken by Abrams' needle, for example, gives a diagnosis in less than $50 \%$ of cases. ${ }^{20}$ Ultrasound or CT guided cutting needle biopsy specimens give much better results and thoracoscopic biopsy under direct vision will yield a diagnosis in most cases. ${ }^{21}$ Open biopsy is occasionally necessary, but even then the diagnosis may remain elusive and may only be confirmed at necropsy. This is because the tumour often evokes a marked fibrous response and the malignant tissue may be missed by the biopsy.

The main pathological types are epithelioid, sarcomatoid (or fibrous), and biphasic (or mixed). The biphasic type combining epithelioid and sarcomatoid features is easiest to diagnose. The epithelioid type is most common and is easily confused with adenocarcinoma. Pathologists should attempt to specify the histological subtype because it affords prognostic information to the clinician which is helpful in clinical management and important to take into account if the patient is being considered for surgery or a clinical trial. Table 2 is given to guide clinicians to the approach pathologists might take in differentiating malignant epithelioid mesothelioma from pleural adenocarcinoma using special stains.

Histochemical and immunohistochemical stains assist in differentiating epithelioid mesothelioma from adenocarcinoma. The most useful are shown in table 2. Additionally, epithelial membrane antigen (EMA) staining is generally positive if the process is malignant in both mesothelioma and adenocarcinoma, but not if the process represents mesothelial hyperplasia. EMA is therefore helpful if the proliferation is suspicious of malignancy but there is no evidence of invasive activity.

It is not appropriate to report a tumour as "consistent with either adenocarcinoma or mesothelioma" without using a selection of these stains to attempt differentiation, providing that sufficient tissue is available. Any stain may give an atypical result and a conclusion should be reached on the basis of the results of several stains.

In the sarcomatoid variety spindle shaped cells are set in a varying amount of collagenised stroma. When bland spindle cells are set in much stroma, differentiation from scar tissue may be very difficult while, at the other end of the spectrum, markedly pleomorphic cellular foci showing mitotic activity are indistinguish- 
able from other forms of undifferentiated sarcoma and cartilaginous, osseous, muscular, or fatty differentiation may occasionally occur. Immunostains for broad spectrum cytokeratins may assist in differentiating sarcomatoid mesotheliomas, which react positively, from sarcomas, which react negatively. The adoption of nomenclature such as "osteosarcoma of the pleura" for an otherwise typical mesothelioma in an asbestos worker is inappropriate.

Antibodies that react with mesotheliomas but not carcinomas are described but many of them require fresh tissue and are of dubious specificity. Further progress in this field can be expected.

Localised fibrous tumour of the pleura-In the past this tumour has been known as benign or localised mesothelioma. It differs from mesothelioma in being unrelated to asbestos exposure and having a much better prognosis. The tumour is well circumscribed and covered by serosa. Microscopically, the appearances are of a low grade spindle cell neoplasm. Immunocytochemistry shows positive reactions for vimentin and actin but, unlike mesothelioma, negative reactions for cytokeratin and epithelial membrane antigen. In $80 \%$ of cases there is positive staining for CD34 which is also useful in distinguishing it from mesothelioma in which CD34 reactivity is limited to blood vessels.

Multicystic mesothelial proliferation and well differentiated papillary mesothelioma-Multicystic mesothelial proliferation is a rare condition affecting the peritoneum. It has been known by various names, including multicystic mesothelioma, but it is now recognised to be a reactive rather than a neoplastic lesion, unrelated to asbestos exposure. The prognosis is good but the condition tends to recur. Patients are typically young women with a history of pelvic inflammation or surgery who have a multicystic pelvic mass. Microscopically, the cysts are lined by mesothelial cells. Immunocytochemistry and electron microscopy assist differentiation from lymphangioma. Well differentiated papillary mesothelioma is another uncommon benign condition which occurs in the peritoneum of woman of reproductive age.

\section{Key points}

- Pleural fluid cytology and histology of blind biopsy specimens have low diagnostic yield for mesothelioma but are important initial steps in differential diagnosis.

- Ultrasound and CT guided biopsy and thoracoscopic and surgical biopsy techniques should be used to increase the likelihood of accurate diagnosis.

- Pathologists should attempt to specify the histological type of mesothelioma.

- A selection of special stains should be used to help differentiation of mesothelioma and pleural adenocarcinoma.
MANAGEMENT

Treatment strategy

The management of all patients with mesothelioma should be discussed by a multidisciplinary team, as with lung cancer. Essential management points to be considered on diagnosis are:

(1) Is the patient one of the few who will have operable disease?

(2) How should a pleural effusion, if present, be managed?

(3) Do any biopsy sites require prompt radiotherapy?

(4) Should the patient be considered for entry into a trial of chemotherapy?

(5) What are the palliative care requirements?

(6) What are the compensation issues?

Patients potentially suitable for radical surgery have epithelioid tumours of low volume and are otherwise fit for a major operation. These are likely to be few, we estimate $1-5 \%$. Accurate staging (see below) by CT scanning and, in selected cases, MRI scans identifies those potentially suitable for surgery. Staging also provides prognostic information for those unsuitable for surgery.

Those with early epithelioid disease without radiological evidence of lymph node involvement are the best candidates and radical surgery is otherwise seldom appropriate. In such cases early chemical pleurodesis should be avoided as it makes subsequent surgical exploration of the chest to define the extent of the tumour before radical resection virtually impossible. Patients submitted for radical surgery should be given realistic information about the outcome of surgery and should give fully informed consent.

Patients with pain or a chest wall mass should be considered for palliative radiotherapy; prophylactic radiotherapy to biopsy sites should be offered. For many patients it will be sufficient to explain that no form of active treatment offers proven survival benefit but that all possible measures to alleviate symptoms will be employed. However, some patients find it very difficult to accept a treatment policy which does not include any specific anti-tumour therapy and they should be given the opportunity to discuss what may realistically be expected from chemotherapy with an oncologist or respiratory physician interested in chemotherapy for mesothelioma. If the patient opts for chemotherapy to be given, it is reasonable that it should be offered preferably within the context of a clinical trial such as the forthcoming BTS trial which compares active symptom control (ASC) with either ASC plus combination therapy of mitomycin, vinblastine and cisplatin or ASC with the single agent vinorelbine. If no trials are available locally, chemotherapy using one of the regimens which has been reported to have some activity in mesothelioma is an option.

\section{Staging}

The goals of staging are to assess operability and, in patients subsequently deemed to be inoperable, to offer prognostic information.

Traditionally a system based on that first proposed by Butchart ${ }^{22}$ is used. This involves 
classification of the tumour into four stages: stage I (tumour simply confined to the ipsilateral pleura, pericardium, and diaphragm); stage II (tumour invades the chest wall, mediastinal structures, and/or intrathoracic lymph nodes); stage III (penetration of the diaphragm, with or without lymph node involvement outside the chest); and stage IV (distant metastases).

A more detailed staging system based on a TNM system has been suggested by the International Mesothelioma Interest Group (IMIG) (Appendix 2). ${ }^{23}$ In practice, full IMIG staging will require surgical intervention, although CT scanning offers a useful proximation. This is relevant because of increasing evidence that disease extent and nodal status affect prognosis in surgically resected tumours. ${ }^{24}{ }^{25}$ Staging is essential if the possibility of including the patient in a clinical trial of treatment is contemplated.

Fuller details of these staging systems are given in Appendix 2.

Key points

- Staging is essential for correct selection of patients for surgery.

- Staging provides important prognostic information.

- Staging should be undertaken before clinical trials.

Radical surgery

There are no randomised controlled trials to establish the role of surgery. Historical evidence is based on centres reporting large series and recently these centres have included multimodality therapy, which follows radical surgery with chemotherapy and radiotherapy. ${ }^{26}$

Early surgical series of aggressive local control with extrapleuropneumonectomy (EPP) were reported by Butchart. ${ }^{22}$ This extensive operation, which typically involves removal of the pleura, mediastinal lymph nodes, ipsilateral pericardium and diaphragm, reported a high operative mortality and a significant number of early recurrences. This experience emphasised the need for careful and improved patient selection. More recent and larger series from specialist centres of patients treated with aggressive local surgical control, including EPP, have reported much lower operative mortality which approaches that of standard pneumonectomy for lung cancer. However, in centres where few cases have been operated on, this experience may not be repeated and the operative mortality remains high in inexperienced hands, perhaps in excess of $30 \%$.

Virtually all long term survivors after radical treatment have had epithelioid tumours at an early stage. The diagnosis of epithelioid malignant mesothelioma must be secure before surgery. Frozen section at the time of exploratory thoracotomy is to be avoided as the disease is difficult to diagnose under these circumstances, requiring formal histological examination including immunohistochemistry and occasionally electron microscopy.
Patients with stage I or II tumours on the IMIG staging system seem to have the potential for prolonged survival following surgery. Recent series ${ }^{26}$ reporting results of trimodality therapy including EPP in 183 carefully selected patients have reported a 5 year survival of $15 \%$.

The finding of a higher than expected incidence of $\mathrm{N} 2$ nodal involvement in resected specimens (approximately 40\%) and the associated poor survival has led to suggestions from some experienced surgeons that mediastinoscopy should be performed on all patients considered to be surgical candidates. However, mediastinoscopy has its shortcomings and cannot be expected to detect all N2 disease.

Patients must be fit to undergo major thoracic surgery of any kind and are thus unlikely to be elderly and have associated general medical conditions; this is discussed in another BTS guideline. ${ }^{27}$ Age, however, has not been an exclusion factor in larger reported series where up to $27 \%$ of patients were over 65 years of age.

Key points

- There are no randomised control trials to establish the role of radical surgery.

- Radical surgery should only be considered when there is a positive diagnosis of epithelioid mesothelioma.

- Surgery should only be performed in centres where there is an interest and experience in performing extrapleuropneumonectomies.

- The limited evidence available has reported surgical results only as part of a multimodality treatment strategy.

\section{Management of pleural effusions}

There are a number of problems associated with management of pleural effusions associated with mesothelioma. On the one hand, the clinician would like to avoid invasive measures for inoperable disease wherever possible but, equally, the prospect of recurrent pleural aspiration with the attendant risk of needle track spread of the disease is best avoided.

An early problem is to decide how aggressive to be when the patient first presents with an undiagnosed pleural effusion in whom mesothelioma is strongly suspected. Early thoracoscopic intervention may be important, given the low diagnostic yield of closed procedures. Thoracoscopic intervention allows not only safe removal of all the pleural fluid but also biopsy specimens can be taken to facilitate histological diagnosis and pleurodesis can be performed at the same time.

There are no clinical trials to suggest whether the outcome of patients with effusions referred early for thoracoscopy is better than those treated medically, and it is likely that each patient has to be managed according to the particular circumstances, including access to a thoracic surgical unit. Generally, early pleurodesis-either medical or surgical-is preferable to repeated pleural aspirations for inoperable patients, although pleural aspirations may be appropriate for frail patients with 
advanced disease. In many centres medical pleurodesis may be the most rapidly available option for logistical reasons.

Thoracic surgery is valuable for the control and prevention of recurrence of pleural effusion in patients with histologically proven disease who are unsuitable for radical treatment. Thoracoscopy with talc poudrage has a high success rate ${ }^{28}$ which is enhanced when there is complete drainage of pleural fluid and apposition of the parietal and visceral pleurae. ${ }^{29}$ Success is increased if suction is applied to the intercostal drain postoperatively. Drains are usually removed after 24 hours or once the intercostal drainage is less than $150 \mathrm{ml}$ in 24 hours.

Open pleurectomy and decortication is effective in controlling pleural effusions, but it is invasive and is likely to have high operative mortality (about 30\%) and morbidity and should only be considered in difficult situations. However, video-assisted thoracic surgery (VATS) is now available in most thoracic surgical centres. This technique allows for partial pleurectomy extending up to cytoreductive surgery to be performed with a low morbidity and mortality (about $1.5 \%$ for all VATS procedures); there are low recurrence rates in patients whose effusions have been resistant to other forms of treatment. ${ }^{30}$ This treatment, which may prove to be the technique of choice, requires further evaluation and should be subjected to a randomised trial.

The risk of tumour seeding at drain and port sites following surgical interventions for malignant mesothelioma is considered to be high. This risk can be significantly reduced by early local radiotherapy.

Pleuroperitoneal shunts can be considered for the small number of patients in whom it is not possible to achieve apposition of the pleural surfaces due to trapped lung and persistence of pleural fluid. These shunts can be inserted at mini-thoracotomy and laparotomy or by minimally invasive techniques. There is, however, a high failure and complication rate including blockage of the shunt and peritoneal seedings.

\section{Key points}

- Talc pleurodesis is probably the treatment of choice for the control of pleural fluid.

- VATS pleurectomy is an effective treatment to control pleural fluid in mesothelioma and is much safer than open pleurectomy and decortication.

- The value of pleuroperitoneal shunts remains uncertain.

\section{Radiotherapy}

Irradiation of large volumes of the thorax can result in a high incidence of lung damage. Elegant techniques are available which aim to deliver a high dose to the pleura, minimising the dose to the underlying lung. These techniques remain under investigation and there is no evidence to support the use of radical radiotherapy as a single modality therapy. Radical radiotherapy in combination with sur- gery and chemotherapy is under investigation as part of multimodality therapy and is subject to ongoing studies. Palliative radiotherapy may be effective in relieving pain while prophylactic radiotherapy to drain and biopsy sites and chest wall masses is indicated.

Prophylactic radiotherapy following any invasive procedures (whether drainage or biopsy) - There is a risk of seeding along the track and this may result in a painful mass, although the risk of clinically important disease is unknown. Radiotherapy to the drain site with $21 \mathrm{~Gy}$ in three daily fractions in a randomised study of 40 patients reduced the risk of seeding from $40 \%$ to zero. ${ }^{31}$ A non-randomised study published at around the same time with the same fractionation scheme and $250 \mathrm{kV} x$ rays reported no recurrences in 38 sites irradiated in 20 patients. ${ }^{32}$ It is noteworthy that, in an earlier non-randomised study, Boutin et $a l^{33}$ had observed recurrences when the radiotherapy was delayed for 2 months. The recommendation is that radiotherapy should be given within 4 weeks. Depending on local arrangements, it may help to book the radiotherapy before the procedure is carried out.

Palliative radiotherapy for pain or chest wall masses-In two retrospective series pain improved in 23 of 37 patients $(62 \%) .^{34}{ }^{35}$ Davis et $a l^{36}$ incorporating Ball and Cruickshank, ${ }^{37}$ found that first courses of palliative radiotherapy resulted in improved symptoms in at least 43 of 87 patients (49\%). This is probably an underestimate as the response was unknown in 15 of the patients. These series also included patients with superior vena caval obstruction (SVCO) and metastatic disease. Objective response of chest wall masses was seen in five out of nine patients. ${ }^{35}$ In these series a variety of radiotherapy regimens was used. Most UK clinical oncologists would use a short course of treatment of generally no longer than 2 weeks' duration with the actual regimen being determined by performance status and the size of the treatment field.

Breathlessness is rarely improved by radiotherapy. Pain relief may be disappointingly short lived and there is no evidence for a dose response relationship to radiotherapy under these circumstances.

Palliative radiotherapy to other sites-None of the nine patients with SVCO had relief of symptoms. ${ }^{34}{ }^{36}$ Stenting is therefore recommended as first line treatment for SVCO when it occurs.

Future directions-An additional BTS/MRC trial has been proposed comparing two radiotherapy regimens for prophylactic radiotherapy (21 Gy in three fractions and a single fraction of $14 \mathrm{~Gy})$. Randomised trials of palliative radiotherapy are required. A non-randomised study with prospective recording of symptoms and quality of life is in progress and should pave the way for future randomised studies. 
Key points

- Prophylactic radiotherapy reduces chest wall implantation following invasive procedures.

- Palliative radiotherapy provides pain relief in about half of all patients.

- Palpable masses respond to radiotherapy in about half of all patients.

- Breathlessness and superior vena caval obstruction rarely respond to radiotherapy.

Chemotherapy

Most of the available chemotherapeutic agents have been tried in mesothelioma but none has consistently produced a response rate above $20 \%{ }^{38}{ }^{39}$ Agents which have consistently been reported to produce response rates of $10-20 \%$ include doxorubicin, epirubicin, mitomycin, cyclophosphamide, ifosfamide, cisplatin, carboplatin, and antifolates. Combination chemotherapy trials have not demonstrated consistently greater response rates than single agent trials. There are no published randomised studies which show improved survival in patients treated with chemotherapy compared with supportive care. Symptomatic improvement has been reported following chemotherapy, both in patients with and those without demonstrable tumour regression. ${ }^{40}$ However, no randomised studies have compared the effects of chemotherapy and best supportive care on symptoms and quality of life.

There is a need to continue to explore new agents and new approaches in phase I and II trials and to evaluate regimes which appear to show activity in larger randomised trials. Comparison of different chemotherapy regimens and comparison of chemotherapy with best supportive care would be appropriate, particularly in patients with few symptoms. End points should include tumour response as assessed by serial CT scans, quality of life, and survival.

The proposed BTS/MRC trial compares active symptom control (ASC) with ASC and either three agents (mitomycin, vinblastine and cisplatin) or a single agent (navelbine). All patients should be offered the opportunity to discuss what chemotherapy may offer with an oncologist or respiratory specialist with an interest in management of mesothelioma as part of their multidisciplinary care. For those who wish to have chemotherapy it is reasonable that it should be offered, preferably within the context of a clinical trial.

Key points

- All patients with mesothelioma should have the opportunity to discuss the pros and cons of chemotherapy with either an oncologist or a respiratory specialist.

- There are no published randomised trials comparing either survival or symptom control in patients treated with chemotherapy or best supportive care.

- Chemotherapy, where used, should be given as part of a clinical trial.
- Clinicians should be encouraged to enter patients into suitable trials.

New approaches to treatment

New approaches to treatment are under investigation. Some patients are well informed about these, increasingly frequently as a result of searching the internet.

Various types of gene therapy have been proposed. These include introduction of "suicide genes" which make the tumour cells susceptible to antiviral agents, and genes to stimulate natural defence mechanisms against tumours (such as cytokine genes to stimulate natural killer cell activity and the heat shock protein gene to increase presentation of tumour antigens). ${ }^{41}$ These studies are all at a very early stage and are not yet realistic options for treatment.

Photodynamic therapy employs a red laser light to activate drugs which have a cytotoxic effect. A randomised trial found no benefit from this mode of therapy added to debulking surgery. ${ }^{42}$

Various types of immunotherapy have been tried, including intrapleural and systemic interleukin 2 and interferon. ${ }^{43}$ Occasional responses have been observed but there is no evidence that these treatments are superior to chemotherapy.

\section{Key point}

- Gene therapy, photodynamic therapy, and immunotherapy do not yet have an established role.

\section{Palliative care}

Palliative care of the patient with mesothelioma and the family has an important part to play, given that the disease has a uniformly pooralthough relatively well defined-prognosis. Most patients need symptom palliation from the time of diagnosis onwards. It needs to be recognised that all symptoms have a context which is physical, psychological, and social. If the context is not heeded, symptom relief may be suboptimal. Palliative care aims to provide relief from pain and other physical symptoms and to respond to psychological, social, and spiritual needs.

The patient, the family, and the general practitioner may often have difficulty in accepting that palliative care is the only available treatment for the great majority of cases. Anger and frustration are common, and there are particular issues in mesothelioma concerning blame for the disease, obtaining pensions, and litigation.

This document does not present a comprehensive account of palliative care and symptom relief and more details can be found in standard references. ${ }^{44} 45$

\section{Key points}

- Most patients need symptom palliation from the time of diagnosis onwards.

- Palliative care should aim to provide relief from pain and other physical symptoms and to respond to emotional, 
psychological, social, and spiritual needs.

General management-Patients with mesothelioma should be under the care of a specialist, usually a respiratory physician who should be able to liaise with a cardiothoracic surgeon, an oncologist with a special interest in thoracic oncology, a specialist palliative care team, and a pain relief service.

The specialist should ensure that the diagnosis is communicated skilfully and sympathetically. A clear picture of the disease and what to expect, including a realistic prognosis, should be given to the patient and, if appropriate, to families and carers. However, it is important never to imply that "nothing can be done".

Immediate communication with the general practitioner should include the known extent of the disease, what was said to the patient, and the management plan. ${ }^{46}$

Physicians should ensure that relatives or carers and the general practitioner are warned, at an appropriate stage, that a Coroner's post mortem will nearly always be required after the death of a patient with mesothelioma, and all deaths have to be reported to the Coroner (in Scotland the Procurator Fiscal).

Patients and families should have access to written information about both the disease and organisations with a specific interest in asbestos related disorders, cancer, and life threatening illness. A list of available organisations is given in Appendix 3.

There should be involvement of an appropriately trained specialist nurse who can facilitate the pathway of care of the patient and the family throughout the illness, and ensure good liaison between hospital services and primary care, and access to specialist palliative care services as required. Patients should be made aware of whom to contact in case of need.

Appropriate regular outpatient follow up is recommended, even if there is no change in treatment, as it provides an opportunity for further discussion including issues of compensation and benefits. There should be continuing close liaison with the general practitioner and primary health care team.

\section{Key points}

- Patients with mesothelioma should be under the care of a specialist.

- The specialist should ensure that the diagnosis is communicated skilfully and sympathetically with a clear picture of the disease and the management plan.

- This information should be communicated immediately to the general practitioner.

- Written information about the disease and relevant organisations should be available to the patient and family.

- An appropriately trained specialist nurse should be involved from the outset to support the care of the patient and liaise between hospital services, primary care, and specialist palliative care services.
- The general practitioner should be reminded that all deaths have to be reported to the Coroner (in Scotland the Procurator Fiscal); a post mortem is usually required.

Symptom control-All symptoms need a working diagnosis. Some may be caused by intercurrent non-cancer related problems. It is often helpful to record symptom severity on a simple scale to assess progress and response to treatment.

(1) Pain relief. Analgesic use should follow the standard WHO "analgesic ladder" with the use of appropriate laxatives. Analgesics, especially opiates, should be given regularly with adequate escape medication for intermittent breakthrough pain. In pain from chest wall involvement the response to opiates is variable because of added inflammatory and neuropathic components. In such cases adjuvant analgesics such as non-steroidal anti-inflammatory drugs (NSAIDs), amitriptyline, anticonvulsants, and steroids should be considered early.

If the pain is not easily and well controlled by these drugs, then referral to a pain relief service is advised, because other pain relief techniques can be useful. These will depend on local expertise and availability and include TENS machines, intercostal or paravertebral nerve blocks, interpleural, ${ }^{47}$ epidural or intrathecal analgesic infusions, local thoracic spine neurolytic blocks, or percutaneous cervical cordotomy. ${ }^{48}$ Localised pain associated with tumour invasion of the chest wall may respond to radiotherapy. ${ }^{36}$ The role of chemotherapy in pain relief is as yet uncertain. Pain control may be improved by attention to emotional, psychosocial, and spiritual problems.

(2) Breathlessness. The common causes of breathlessness in mesothelioma are pleural effusion, lung compression, and chest wall stiffness. Weakness and malaise, and anxiety or panic, may contribute. If dyspnoea worsens acutely, additional problems to consider include increasing pain, pulmonary embolism, pulmonary vessel invasion by tumour, chest infections, and contralateral pleural or pericardial spread. The treatment of breathlessness due to progressive disease and lung compression is difficult. Breathing exercises and relaxation training combined with re-adaptation (as in pulmonary rehabilitation programmes) and relief of anxieties, fears, and psychosocial problems can reduce the impact of breathlessness, particularly when associated with panic. ${ }^{49}$ Drug therapy for severe breathlessness includes the use of opiates and benzodiazepines. The use of oxygen is discussed fully elsewhere..$^{50}$ In the terminal phase it is often appropriate to use a combination of diamorphine and midazolam in a subcutaneous infusion via syringe driver.

(3) Cough. A persistent cough is probably due to lung compression and is common in 
patients with mesothelioma. Symptomatic trials of opiate linctuses, oral steroids, and nebulised local anaesthetics can be considered. ${ }^{51}$

(4) Anorexia, weight loss, and fatigue syndrome. This is common in the later stages of mesothelioma. Treatment is unsatisfactory but gastric prokinetic agents, steroids, and megestrol acetate have been tried. ${ }^{52}$ Dietary advice and experimentation can be helpful. Depression may mimic this syndrome and respond to appropriate treatment.

(5) Other problems. Generalised troublesome sweating can occur. This sometimes responds to paracetamol, NSAIDs, cimetidine, or thioridazine (10-30 mg nightly)..$^{53}$ Occasionally, patients have lymphatic or local spread resulting in dysphagia or SVCO (for both of which stents can be considered) or leg oedema (for which referral to a lymphoedema therapist is advised). Metastases commonly occur late in the disease and are rarely symptomatic. Their management is as for metastases due to other cancers. Confusion can be a problem in the later stages of the disease and underlying causes should be identified and treated before symptomatic drugs are prescribed. Possible causes include drug toxicity (particularly opiates), infection, hypoxia, uncontrolled pain, and fear. Haloperidol is the drug of choice. ${ }^{54}$

\section{Key points}

- Early involvement of a pain relief service is often needed.

- Breathlessness is often multifactorial and a variety of approaches may be necessary for palliation.

\section{Peritoneal mesothelioma}

The incidence of peritoneal disease, like pleural mesothelioma, has been steadily increasing over the last 30 years, although recently the ratio of pleural to peritoneal disease in an asbestos exposed population has been in the order of 12:1 and is slowly increasing. ${ }^{55}$ Factors favouring the development of peritoneal disease appear to be longer, heavier exposure to asbestos and, perhaps, to mixed dust. Although the age distribution is similar to pleural disease, there is less male preponderance. ${ }^{5657}$

\section{PATHOLOGY}

The disease may be localised, multinodular, or diffuse. Epithelioid subtypes are much more common with only about $15 \%$ of tumours being either mixed or sarcomatoid. In two thirds of patients the disease remains confined to the abdomen. The undersurface of the diaphragm is almost always involved but tumour rarely penetrates through into the thorax. Spread to the omentum, pelvis, and right subhepatic space is common.

Well differentiated papillary and cystic mesotheliomas seem to be a separate disease, distinct from malignant peritoneal tumours.
These conditions are unrelated to asbestos exposure and have a good prognosis.

\section{SYMPTOMS}

These are non-specific and include abdominal pains, cramps, constipation, weight loss, abdominal distension, and ascites. ${ }^{59}$ Small bowel obstruction is usually a feature of the terminal stages.

\section{IMAGING}

Imaging may suggest the diagnosis and the optimal modality is probably CT scanning. This may show omental and mesenteric thickening (the commonest findings), sheet-like masses, tumour nodules, and usually only minimal ascites which may be loculated. Retroperitoneal nodal enlargement is more in favour of an adenocarcinoma (usually from ovary, stomach, colon or breast). Differential diagnosis includes peritoneal secondaries from adenocarcinoma, peritoneal endometriosis, and pseudomyxoma peritonei.

\section{DIAGNOSIS}

Cytological examination of the ascitic fluid rarely gives an answer but fine needle aspiration of omental masses has been advocated. ${ }^{60}$ If the diagnosis is suspected, this can be confirmed by laparoscopy ${ }^{61}$; previously, many of these patients underwent diagnostic laparotomy.

\section{PROGNOSIS AND TREATMENT}

The prognosis is worse than for pleural mesothelioma. In one study the mean survival time was 7.4 months compared with 11.4 months in a group with pleural mesothelioma. Like pleural mesotheliomas, the epithelioid subtype seems to be associated with a better prognosis, as is youth and a good performance status. In most patients the prognosis is poor. There is little evidence to support the benefit of chemotherapy, although occasional responses are reported and small case series suggest prolonged survival with regimes based on cisplatin and including mitomycin $\mathrm{C}$ and doxorubicin. The role of radiotherapy is unclear but is associated with considerable morbidity. It has been suggested $^{62}$ that debulking procedures may improve the response to chemotherapy but there are no controlled trials.

It is important to remember that the management of peritoneal mesothelioma should also include multidisciplinary patient care and consideration of medicolegal aspects.

\section{Key points}

- Peritoneal mesothelioma is related to asbestos exposure but is less common than pleural mesothelioma.

- The outlook is poor and no treatment has been shown to alter prognosis.

\section{Benefits and medicolegal aspects} COMPENSATION FOR ASBESTOS INDUCED MESOTHELIOMA

The respiratory specialist is often best placed to advise patients and families about opportunities for compensation. The legal test is that the diagnosis and causation should be established 
on the balance of probability. Hence, pathological diagnosis is not mandatory for compensation issues although an unequivocal diagnosis will remove subsequent room for debate. Patients who cannot identify exposure to asbestos are not eligible for compensation.

Patients may be entitled to claim compensation in two ways:

(1) A claim for Industrial Injuries Disablement Benefit from the Department of Social Security (via the Benefits Agency).

(2) A Common Law claim for damages from the firm/firms where exposure to asbestos occurred.

Industrial Injuries Disablement Benefit Industrial injuries benefit is awarded under the terms of the Social Security Contributions and Benefits Act 1992. This Act specifies that the following criteria must be met to qualify for industrial injuries benefit:

(a) The person must be suffering from a prescribed disease or personal injury which developed after 4 July 1948.

(b) (i) The claimant must have been an employee, i.e. not self-employed; and

(ii) he should have worked in a scheduled occupation-that is, one where there was exposure to asbestos.

Mesothelioma is designated a prescribed disease (D3) under Schedule 1 of the Social Security (Industrial Injuries) (Prescribed Diseases) Regulations 1985. Under new regulations (The Social Security (Industrial Injuries) (Miscellaneous Amendment) Regulations 1997) the schedule of prescribed occupations has been broadened to include any occupation in which there has been "exposure to asbestos, asbestos dust or any admixture of asbestos at a level above that commonly found in the environment at large".

This alteration means that anyone, whatever their occupation, who is diagnosed as having mesothelioma should have a detailed occupational history taken to see whether they have ever been exposed to asbestos, even for a short period, while carrying out their work. Their work may not have involved the handling of asbestos but may have been carried out in its presence.

Procedure for claiming benefit-A claim for Industrial Injuries Disablement Benefit is made by contacting the local Benefits Agency (local telephone directory or enquiry line 0800 882200). Leaflets SD5 "Ill or Disabled Because of Work" and NI12 "If you have an Industrial Disease" may be useful. It may be helpful to patients if a supply of these forms is obtained by chest clinics. Occasionally the claimant may need some help with completing the form and this can usually be obtained from the trade union, a social worker, a relative, the general practitioner, or the doctor advising the patient to make a claim.

War Pensions Scheme-Mesothelioma caused by asbestos exposure during service in the defence forces is compensated under the War Pensions Scheme. A claim should be registered with the
War Pensions Agency (helpline 01253 8588858).

Benefits payable for incapacity and disabilityPatients should obtain Benefits Agency leaflet SD1 "Sick or Disabled" (available in tape, Braille and a number of languages) and the following benefits are available:

(a) Income replacement:

(i) For those with adequate National Insurance contributions: Statutory Sick Pay (SSP) or Occupational Sick Pay from the employer for the first 6 months of illness or Short Term Lower Rate Incapacity Benefit where there is no employer to pay; in either case then Incapacity Benefit.

(ii) For those with inadequate National Insurance contributions: Income Support for those whose income and capital is below specified limits and/or Severe Disablement Allowance after 28 weeks of incapacity for work.

(b) Help with excess costs of disability:

(i) For those with an assessment for Industrial Injuries Disablement Benefit of $100 \%$, Constant Attendance Allowance (CAA) is available.

(ii) For those not entitled to CAA, Disability Living Allowance (DLA) is available for those whose disability began before their 65th birthday and Attendance Allowance (AA) is available for those whose disability began on or after their 65 th birthday.

\section{Common Law Compensation}

We suggest that clinicians seeing any case of asbestos related lung disease should advise the patient to consider seeking legal advice promptly. This will reduce the risk of subsequent claims for mesothelioma being statute barred (see below).

Damages may be recovered from an employer by suing the employer for negligence. The claimant must show that, on the balance of probabilities, his injuries and/or disability are due to his occupational exposure to asbestos, this exposure being attributable to the employer's negligence in maintaining the standards required by the common law. It may also be possible to sue the employer for a breach of his/her statutory duty to comply with specific health and safety regulations. Claims can also be made against a former employer's insurer, even if the employer is no longer in business.

Proceedings for these claims must be started within 3 years of the claimant's "date of knowledge" of any injury caused by asbestos exposure, including pleural plaques, which is different from 3 years after first being exposed to the risk. A claim brought after the expiry of 3 years is generally "statute barred" and is unable to be pursued in the courts. The date of knowledge is based on when the claimant first becomes aware (i) that the injury is significant; (ii) that the injury is attributable in whole or in part to the act/omission alleged to constitute the negligence or breach of duty; and (iii) of the identity of the defendant. The date of knowl- 
edge is not always going to be the first time a potential claimant is examined by a doctor. The claimant is expected to make reasonable inquiries himself as to the cause of his disability. The courts also have the discretion to extend the 3 year time limit but this remains only a discretion and the claimant will have to persuade the court to do so.

COMPENSATION UNDER THE PNEUMOCONIOSIS

ETC (WORKERS' COMPENSATION) ACT 1979

For those in whom neither an employer nor an insurer can be identified, a claim can be made to the Department of Environment, Transport and the Regions under the Pneumoconiosis etc (Workers' Compensation) Act 1979. The purpose of this scheme is to provide lump sum payments to or in respect of certain persons who are, or were immediately before they died, disabled by pneumoconiosis, byssinosis or diffuse mesothelioma, and for connected purposes. Eligibility for an award depends on the following criteria being fulfilled: (i) that disablement benefit is payable to the claimant in respect of the disease; (ii) that every relevant employer of his has ceased to carry on business; and (iii) that he has not "brought any action, or uncompromised any claim, for damages in respect of the disablement". This last criterion means that, if the claimant has already begun a damages claim against the employer and has either settled that claim or that claim ended because the evidence against the employer was weak, then he will not be eligible for a payment under the scheme of this Act.

\section{Appendix 1: Membership of the BTS} Working Party

Dr M G Britton, Consultant Chest Physician, St Peter's Hospital, Chertsey, Surrey KT16 0PZ

Mr M Cowen (Association of Cardiothoracic Surgeons \& Research Committee), Castle Hill Hospital, Cottingham, Hull HU16 5JQ

Dr M A Greenstone, Consultant Physician, Castle Hill Hospital, Cottingham, Hull HU16 5JQ

Dr M Hetzel, Consultant Physician, Bristol Royal Infirmary, Bristol BS2 8HW

Dr C Higgs, Medical Director, The Dorothy House Foundation, Winsley, Bradford-on-Avon, Wiltshire BA15 2LE

Dr M F Muers, Consultant Physician, The General Infirmary at Leeds, Leeds, West Yorkshire LS1 3EX

Dr C $\mathbf{R}$ McGavin, Consultant Chest Physician, Plymouth Chest Clinic, Derriford Hospital, Freedom Fields, Plymouth, Devon PL6 8DH

Dr R Rudd, Consultant Physician, London Chest Hospital, London E2 9JX

Dr J Wiggins (Chairman and Editor of Statement), Consultant Physician, Wexham Park Hospital, Wexham, Slough, Berkshire SL2 4HL

Additional contributions were obtained from: Professor B Corrin, Emeritus Professor of Pulmonary Histopathology, Royal Brompton \& Harefield NHS Hospitals Trust, Sydney Street, London SW3 6NP Dr $\mathbf{P} \mathbf{R}$ Goddard, Consultant Radiologist, Bristol Royal Infirmary, Bristol BS2 8HW

Dr M O'Brien, Consultant Medical Oncologist, The Royal Marsden NHS Trust, Sutton, Surrey SM2 5PT

Mr M Osborne, Solicitor, Field Fisher Waterhouse, 35 Vine Street, London EC3N 2AA

Dr R J H Robertson, Consultant Radiologist, The General Infirmary at Leeds, Leeds, West Yorkshire LS1 3EX

Dr N P Rowell, Consultant in Clinical Oncology, The Royal Marsden NHS Trust, Sutton, Surrey SM2 5PT

\section{Appendix 2: Staging}

BUTCHART STAGING SYSTEM

Stage I: Tumour contained within capsule of the parietal pleura, lung, pericardium, diaphragm.

Stage II: Tumour invades chest wall or mediastinum: oesophagus, heart, opposite pleura. Positive chest lymph nodes.

Stage III: Tumour invasion through diaphragm to peritoneum: opposite pleura. Positive lymph nodes outside chest.

Stage IV: Distant blood-borne metastases.

INTERNATIONAL MESOTHELIOMA INTEREST

GROUP (IMIG) STAGING SYSTEM

Primary tumour (T):

T1a: Tumour limited to the ipsilateral parietal including mediastinal and diaphragmatic pleura, no involvement of the visceral pleura.

T1b: Tumour involving the ipsilateral parietal including mediastinal and diaphragmatic pleura, scattered foci of tumour also involving the visceral pleura

T2: Tumour involving each of the ipsilateral pleural surfaces (parietal, mediastinal, diaphragmatic and visceral pleura) with at least one of the following features: involvement of diaphragmatic muscle; confluent visceral pleural tumour (including the fissures) or extension of tumour from visceral pleura into the underlying pulmonary parenchyma.

T3: Describes locally advanced but potentially resectable tumour; tumour involving all of the ipsilateral pleural surfaces (parietal, mediastinal, diaphragmatic and visceral pleura) with at least one of the following features: involvement of the endothoracic fascia; extension into the mediastinal fat; solitary, completely resectable focus of tumour extending into the soft tissues of the chest wall, non transmural involvement of the pericardium.

T4: Describes locally advanced technically unresectable tumour; tumour involving all of the ipsilateral pleural surfaces (parietal, mediastinal, diaphragmatic and visceral) with at least one of the following features: diffuse extension or multifocal masses of tumour in the chest wall with or without associated rib destruction; direct transdiaphragmatic extension of tumour to the peritoneum; direct extension of tumour to the contralateral pleura; direct extension of tumour to one or more mediastinal organs; direct extension of tumour into the spine: tumour extending through to the internal surface of the pericardium with or without a pericardial effusion; or tumour involving the myocardium.

Lymph nodes $(\mathbf{N})$ :

Nx: Regional lymph nodes cannot be assessed.

N0: No regional lymph node metastases.

N1: Metastases in the ipsilateral bronchopulmonary or hilar lymph nodes.

N2: Metastases in the subcarinal or the ipsilateral mediastinal lymph nodes including the ipsilateral internal mammary nodes.

N3: Metastases in the contralateral mediastinal, contralateral internal mammary, ipsilateral or contralateral supraclavicular lymph nodes.

Metastases (M):

Mx: Presence of distant metastases cannot be assessed.

M0: No distant metastasis.

M1: Distant metastasis present.

Staging:

Stage Ia: T1 aNOM0

Stage Ib: T1bNOM0

Stage II: T2NOMO

Stage III: any T3M0, any N1M0, any N2M0

Stage IV: any T4, any N3, any M1

Appendix 3: Sources of information and help available for patients and carers

This Appendix lists some of the national organisations which can provide information and support to patients and carers. Each specialist should be aware of other 
local organisations which may provide similar services and practical help.

MESOTHELIOMA OR ASBESTOSIS

(1) National Mesothelioma Helpline (funded by Macmillan Cancer Relief)

Telephone advice for patients, their family and carers is available from Mrs Mavis Robinson, Mesothelioma Information Project Manager, Cookridge Hospital, Leeds 16 (telephone 0113 3925294). An information booklet on mesothelioma for patients and carers written by Mavis Robinson may be available.

(2) Asbestos Related Diseases Association 26 Tollerton Green, Highbury Vale, Nottingham NG6 7EX (telephone/fax: 0115927 5108).

Self-help group for sufferers from conditions related to asbestos and their carers. Assistance with benefits and compensation claims, counselling, monthly newsletter, association meetings, and social activities.

CANCER

(1) Cancer BACUP

Head Office: 3 Bath Place, Rivington Street, London EC2A 3JR. The Cancer Information Service is open from Monday to Friday from $10.00 \mathrm{am}$ until $7.00 \mathrm{pm}$ (telephone 0800 181199). The Cancer Counselling Service is open from Monday to Friday from 9.30 am until 5.00 pm (telephone 0207 696 9000; in Scotland 0141553 1553).

A registered charity providing information about all aspects of cancer as well as emotional support for cancer patients and their families. BACUP's Cancer Support Service is staffed by specialist oncology nurses and trained cancer counsellors. It is supported by a panel of cancer specialists and advisers. Publications are available on all types of cancer treatments and support issues, including a factsheet on mesothelioma, and a newsletter "BACUP News" is produced three times a year.

\section{(2) Cancer Link}

11-21 Northdown Street, London N1 98N. Freephone Cancer Information Helpline (telephone 0800 132905; textphone available for deaf and hard of hearing people). Freephone MAC Helpline for young people affected by cancer (telephone 0800 591023). Freephone Asian Cancer Information Helpline in Bengali, Hindi, Punjabi, Urdu and English (telephone: 0800 590415).

Provides emotional support and information in response to telephone enquiries and letters on all aspects of cancer to people with cancer, their families, friends, carers and professionals working with them. Runs one-to-one network of people affected by cancer and publishes booklets, including a booklet on complementary therapies and cancer, factsheets, videos, and audiotapes in seven languages. Publishes a nationwide directory of cancer self-help groups.

(3) Macmillan Cancer Relief

Anchor House, 15/19 Britten Street, London SW3 3TZ (telephone 02073517811 ).

Macmillan Cancer Relief supports and develops services to provide specialist care for people with cancer at every stage of their illness including Macmillan nurses. Information on services available on request. Also provides financial help through patient grants which can be applied for through hospital and hospice nurses, social workers, and other health care professionals.

(4) Scotland

Taktent Cancer Support: Resource and Information (telephone 0141221 1932).

(5) Wales

Tenovus Cancer Information Centre (freephone helpline 0800526527 ).

(6) Northern Ireland

The Ulster Cancer Foundation (helpline 01232 663439 weekdays $9.30-12.30$ ).
(7) Eire

Irish Cancer Society (helpline 1800200 700).

CARERS' ASSOCIATIONS

Carers' National Association

Ruth Pitter House, 20-24 Glasshouse Yard, London EC1A 4JS (telephone 0207490 8818). Carers' line: Monday to Friday 1-4 pm (telephone 0207490 8898).

GENERAL HELP WITH GRANTS AND BENEFITS AND LEGAL ADVICE

(1) Local Citizens' Advice Bureau

(2) DSS Benefit Enquiry Line

General advice on Social Security benefits. Help with completing claim forms. DSS freephone for any enquiry: 0800882200 .

(3) Occupational and Enviromental Diseases Association (OEDA)

Mitre House, 66 Abbey Road, Bush Hill Park, Enfield, Middlesex EN1 2QH (telephone 0181360 8490).

Can supply information on specialist solicitors and give advice on claims etc.

(4) Association of Personal Injury Lawyers (APIL)

Telephone 0115958 0585. (In Scotland, SALARC: legal advice and information pack. Telephone 0141 552 3366)

(5) There are a number of solicitors' firms who, because of their locality and special interest, have experience in handling claims about asbestos related diseases including mesothelioma. Patients should be advised to consider whether a prospective law firm has such experience and appropriate questions should be asked of the firm, including the number of cases handled by the firm, the number that have reached the courts, and how quickly asbestos related claims are processed.

1 Peto J, Hodgson JT, Matthews FE, et al. Continuing increase in mesothelioma mortality in Britain. Lancet 1995;345:535-9.

2 Hubbard R. The aetiology of mesothelioma: are risk factors other than asbestos exposure important? Thorax 1997;52: 496-7.

3 McDonald JC. Health implications of environmental exposure to asbestos. Environ Health Perspect 1985;62:319-28.

4 Yates DH, Corrin B, Stidolph PN, et al. Malignant mesothelioma in south east England: clinicopathological experience of 272 cases. Thorax 1997;52:507-12.

5 Peto J, Seidman H, Selikoff IJ. Mesothelioma mortality in asbestos workers: implications for models of carcinogenesis and risk assessment. Br f Cancer 1982;45:124-35.

6 Doll R, Peto J. Asbestos: effects on health of exposure to asbestos. London: HMSO, 1985.

7 World Health Organization. Crysotile asbestos. Environmental Health Criteria 203. Geneva: World Health Organizatal Health Criteria
tion, 1998:144.

8 Elmes PC, Simpson MJC. The clinical aspects of mesothelioma. $Q$ F Med 1976;45:427-49.

9 Hillerdahl G. Malignant mesothelioma: review of 4710 published cases. Br $\mathcal{F}$ Dis Chest 1983;77:321-43.

$10 \mathrm{McG}$ avin CR, Hughes PD. Finger clubbing in malignant mesothelioma and benign asbestos pleural disease. Respir Med 1998;92:691-2.

11 Ribak J, Selikoff JJ. Survival of asbestos insulation workers with mesothelioma. Br f Ind Med 1992;49:732-5.

12 Van Gelder T, Damhuis RA, Hoogstedon HC. Prognostic factors and survival in malignant pleural mesothelioma. Eur Respir 7 1994; 7:1035-8.

13 Law MR, Hodgson ME, Heard BE. Malignant mesothelioma of the pleura: relation between histological type and clinical behaviour. Thorax 1982;37:810-5.

14 Leung AN, Muller NL, Miller RR. CT in differential diagLeung AN, Muller NL, Miller RR. CT in differential diag-
nosis of diffuse pleural disease. AfR 1990;154:487-92.

15 Heelan RT. CT and MR imaging in the evaluation of pleural masses. Chest Surg Clin North Am 1994;3:431-50.

16 Patz EF, Shaffer K, Piwnica-Worms DR, et al. Malignant pleural mesothelioma: value of CT and MR imaging in predicting resectability. AfR 1992;159:961-6.

17 McLoud TC. CT and MR in pleural disease. Clin Chest Med 1998;19:261-76.

18 Layer G, van Kaick G. Mesothelioma of the pleura: diagnosis with imaging procedures. Langenbecks Arch Chir Supp Kongressbd 1992;173-9.

19 Renshaw AA, Dean BR, Antman $\mathrm{KH}$, et al. The role of cytological evaluation of pleural fluid in the diagnosis of malignant mesothelioma. Chest 1997;111:106-9.

20 Whitaker D, Shilkin KB. Diagnosis of pleural malignant mesothelioma in life: a practical approach. $\mathcal{F}$ Pathol 1984;143:147-75. 
21 Boutin C, Rey F. Thoracoscopy in pleural malignant mesothelioma: a prospective study of 188 consecutive .

22 Butchart EG, Ashcroft T, Barnsley WC, et al. Pleuropneumonectomy in the management of diffuse malignan mesothelioma of the pleura. Thorax 1976;31:15-24.

23 Rusch VW. A proposed new international TNM staging system for malignant pleural mesothelioma from the International Mesothelioma Interest Group. Lung Cancer 1996; 14:1-12.

24 Sugarbaker DJ, Garcia JP, Richards WG, et al. Extrapleural pneumonectomy in the multimodality therapy of malignant
pleural mesothelioma. Results in 120 consecutive patients. Ann Surg 1996;224:288-94.

25 Rusch VW, Venkatraman F. The important of surgical staging in the treatment of malignant pleural mesothelioma. $f$ Thorac Cardiovasc Surg 1996;111:815-25.

26 Sugarbaker DJ, Flores RM, Jaklitsch MT, et al. Resection margins, extrapleural nodal status; and cell type to margins, extrapleural nodal status; and cell type to determine post-operative long-term survival in trimodality therapy of malignant pleural mesothelioma: results

27 British Thoracic Society and Society of Cardiothoracic Surgeons of Great Britain and Ireland. Guidelines on the selection of patients with lung cancer for surgery. Thorax 2001;56:89-108

28 Kennedy L, Sahn SA. Talc pleurodesis for the treatment of pneumothorax and pleural effusion. Chest 1994;106:121522.

29 Walker-Renard P, Vaughan LM, Sahn SA. Chemical pleurodesis for malignant pleural effusions. Ann Intern Med 1994;120:56-64.

30 Waller DA, Morritt GN, Forty J. Video-assisted thoracoscopic pleurectomy in the management of malignant pleural effusion. Chest 1995;107:1454-6.

31 Boutin C, Rey F, Viallat JR. Prevention of malignant seeding after invasive diagnostic procedures in patients with pleural mesothelioma. A randomised trial of local radiotherapy. Chest 1995;108:754-8.

32 Low EM, Khoury GG, Matthews AW, et al. Prevention of tumour seeding following thoracoscopy in mesotheliom tumour seeding following thoracoscopy in mesothelion

33 Boutin C, Irisson M, Rathelot P, et al. L'extensions parietale des mesotheliomas pleuraux malin diffuse après biopsies: prevention par radiotherapie locale. Presse Med 1983;12: 1823.

34 Gordon W, Antman KH, Greenberger JS, et al. Radiation therapy in the management of patients with mesothelioma. Int F Radiat Oncol Biol Phys 1982;8:19-25.

35 Bissett D, Macbeth FR, Cram I. The role of palliative radiotherapy in malignant mesothelioma. Clin Oncol 1991;3 315-7

36 Davis SR, Tan L, Ball DL. Radiotherapy in the treatment of malignant mesothelioma of the pleura, with special reference to its use in palliation. Austral Radiol 1994;38: 212-4.

37 Ball DL, Cruikshank DG. The treatment of malignant mesothelioma of the pleura: a review of a 5 year experience, othelioma of the pleura: a review of a 5 year experience,
with special reference to radiotherapy. Am 7 Clin Oncol with special

38 Ong ST, Vogelzang NG. Chemotherapy in malignant pleural mesothelioma. A review. 7 Clin Oncol 1996;14:1007-17.

39 Ryan CW, Herndon J, Vogelzang NJ. A review of chemotherapy trials for malignant mesothelioma. Ches 1998;113:66-73S.

40 Middleton GW, Smith IE, O'Brien ME, et al. Good symptom relief with palliative MVP (mitomycin-C, vinblastine and cisplatin) chemotherapy in malignant mesothelioma. Ann Oncol 1988;9:269-73.
41 Albelda SM. Gene therapy for lung cancer and mesothelioma. Chest 1997;111:144-9S

42 Pass HI, Temeck BK, Kranda K, et al. Phase III randomised trial of surgery with or without intraoperative photodynamic therapy and postoperative immunochemotherapy for malignant pleural mesothelioma. Ann Surg Oncol 1997; 4:628-33

43 Upham JW, Garlepp MJ, Musk AW, et al. Malignant mesothelioma: new insights into tumour biology and immunology as a basis for new treatment approaches. Tho$\operatorname{rax} 1995 ; 50: 887-93$

44 Doyle D, Hanks GWC, MacDonald N. Oxford textbook of palliative medicine. 2nd ed. Oxford: Oxford University Press, 1998.

45 Twycross R. Symptom management in advanced cancer. 2nd ed. UK: Radcliffe Medical Press, 1997.

46 British Thoracic Society. BTS recommendations to respiratory physicians for organising the care of patients with lung cancer. The Lung Cancer Working Party of the British Thoracic Society Standards of Care Committee Thorax 1998;53(Suppl 1):S1-8.

47 Amesbury B, O'Riordan J, Dolin S. The use of interpleural analgesia using bupivacaine for pain relief in advanced cancer. Palliative Med 1999;13:153-8.

48 Jackson MB, Pounder D, Price C, et al. Percutaneous cervical cordotomy for the control of pain in patients with pleural mesothelioma. Thorax 1999;54:238-41.

49 Bredin M, Corner J, Krishnasamy M, et al. Multicentre randomised controlled trial of nursing intervention for breathlessness in patients with lung cancer. BM7 1999;318: 901-4.

50 Royal College of Physicians. Domiciliary oxygen services. London: Royal College of Physicians, 1999.

51 Ahmedzai S, Davis C. Nebulised drugs in palliative care. In: Muers MF, Corris PA, eds. Current best practice for nebuliser treatment. The Nebuliser Project Group of the British Thotreatment. The Nebuliser Project Group of the British Tho-
racic Society Standards of Care Committee. Thorax 1997; racic Society Standard
52(Suppl 2):S75-7.

52 Breura E. Pharmacological treatment of cachexia: any progress? Support Care Cancer 1998;6:109-13.

53 Cowap J, Hardy J. Thioridazine in the management of cancer-related sweating. F Pain Symptom Management 1998;15:266.

54 MacLeod AD. The management of delirium in hospice practice. Eur F Palliative Care 1997;4:116-20.

55 Health and Safety Commission. Health and safety statistics 1996/7. London: HSE Books, 1997.

56 Gardner MJ, Jones RJ, Pippard EC, et al. Mesothelioma of the peritoneum during 1967-82 in England and Wales. $\mathrm{Br}$ f Cancer 1985;51:121-6.

57 Browne K, Smither WJ. Asbestos related mesothelioma: factors discriminating between pleural and peritoneal sites. $\mathrm{Br}$ f Ind Med 1983;40:145-52.

58 Moertel CG. Peritoneal mesothelioma. Gastroenterology 1972;63:346-50.

59 Antman KH, Pomfret EA, Aisner J, et al. Peritoneal mesothelioma: natural history and response to chemotherapy. 7 Clin Oncol 1983;1:386-91.

60 Kannerstein M, Churg J. Peritoneal mesothelioma. Hum Pathol 1977;8:83-94.

61 Reuter K, Raptopoulos V, Reale F, et al. Diagnosis of peritoneal mesothelioma: computed tomography, sonography and fine needle aspiration biopsy. AfR 1983;140:1189-94.

62 Averbach AM, Sugerbaker PH. Peritoneal mesothelioma: treatment approach based on natural history. In: Sugerbaker PH, ed. Peritoneal carcinomatosis: drugs and diseases. Boston: Kluwer Academic Publishers, 1996: 193-211. 
seem to be specific to $\mathrm{PCH}$, demonstrating the usefulness of HRCT scanning for diagnosis of this disease. Other previously reported CT findings of the disease include increased soft tissue density of the mediastinum ${ }^{12}$ and mediastinal and hilar lymph adenopathies, ${ }^{7}$ but such findings were absent in our case.

Possible explanations for the stable condition of our case over a long period are either that it was a chance discovery of an early phase of the disease by HRCT scanning or that PCH has separate subtypes with differing speeds of progression. Wider use of HRCT scanning and more extensive understanding of $\mathrm{PCH}$ would resolve this issue in the future.

The authors thank Professor Rubin M Tuder (Department of Pathology-Surgical Pathology Laboratory, University of Colorado Health Sciences Center) and Professor Takesaburo Ogata (Center for Medical Sciences, Ibaraki Prefectural University of
Health Sciences) for their pathological review of the case. This work was supported by funding from the Ministry of Education of Japan.

1 White CW, Sondheimer HM, Crouch EC, et al. Treatment of pulmonary hemangiomatosis with recombinant interferon alfa-2a. N Engl F Med 1989;320:1197-200.

2 Al-Fawaz IM, al Mobaireek KF, al-Suhaibani M, et al. Pulmonary capillary hemangiomatosis: a case report and review of the literature. Pediatr Pulmonol 1995;19:243-8.

3 Wagenvoort CA, Beetstra A, Spijker J. Capillary haemangiomatosis of the lungs. Histopathology 1978;2:401-6.

4 Lippert JL, White CS, Cameron EW, et al. Pulmonary capLippert JL, White CS, Cameron EW, et al. Pulmonary cap-
illary hemangiomatosis: radiographic appearance. $\mathcal{f}$ Thor Imaging 1998;13:49-51.

5 Vevaina JR, Mark EJ. Thoracic hemangiomatosis masquerading as interstitial lung disease. Chest 1988;93:657-9.

6 Domingo C, Encabo B, Roig J, et al. Pulmonary capillary hemangiomatosis: report of a case and review of the literature. Respiration 1992;59:178-80.

7 Dufour B, Maitre S, Humbert M, et al. High-resolution CT of the chest in four patients with pulmonary capillary hemangiomatosis or pulmonary venoocclusive disease. AfR 1998;171:1321-4.

8 Eltorky MA, Headley AS, Winer-Muram $\mathrm{H}$, et al. Pulmonary capillary hemangiomatosis: a clinicopathologic review. Ann Thor Surg 1994;57:772-6.

\section{LETTERS TO THE EDITOR}

\section{Vibration during high frequency ventilation in neonates}

Since there is no report quantifying vibration imposed upon neonates, we prospectively studied the vibration produced during high frequency ventilation (HFV) and compared it with that during conventional mechanical ventilation (CMV) of studied patients and weight matched controls $( \pm 250 \mathrm{~g})$ receiving CMV or breathing spontaneously. A noninvasive accelerometric sensor (Analog Devices ADXL05, Norwood, MA, USA) was placed at the mid sternum or postauricular cranium to measure the linear vibration transmitted to the body and head, respectively (amplitude in time and frequency domains expressed in units of " $g$ ").

From April to October 1998 we enrolled seven neonates treated with HFV (mean (SD) weight $2210(1680) \mathrm{g}$, gestation 32 (7) weeks) and 14 weight matched controls (CMV group: $\mathrm{n}=7,2100$ (1730) g, 31 (8) weeks; spontaneous breathing group: $\mathrm{n}=7$, 2230 (1520) g, 32 (7) weeks). The groups were not different with regard to body weight, length, and head circumference. Neonates received $\mathrm{HFV}$ at a frequency of $12 \mathrm{~Hz}$, mean airway pressure of $14(2) \mathrm{cm} \mathrm{H}_{2} \mathrm{O}$, amplitude of $39(10) \mathrm{cm} \mathrm{H}_{2} \mathrm{O}$, and back up CMV at 6 breaths/min. Higher amplitudes of vibration were detected during $\mathrm{HFV}$ than during CMV $(0.098(0.026) g v 0.017$ (0.006) $g$ at the chest and $0.011(0.003) g v 0.007(0.001) g$ at the cranium, $\mathrm{p}<0.05)$ in six HFV treated neonates. One HFV treated neonate did not tolerate the switch to CMV. The vibrations at the chest and postauricular cranium in seven
HFV treated neonates were higher than those of weight matched controls (fig 1, $\mathrm{p}=0.001$ ), whereas no significant difference was found between the control groups. A higher amplitude of vibration at the chest was found in neonates with an adverse outcome than in normal survivors $(0.136 \quad(0.014) g \quad v \quad 0.087$ $(0.024) \mathrm{g}$, respectively), while demographic data and the duration and amplitude of HFV were not different. Interestingly, the vibration at the chest exceeded the limit of whole body
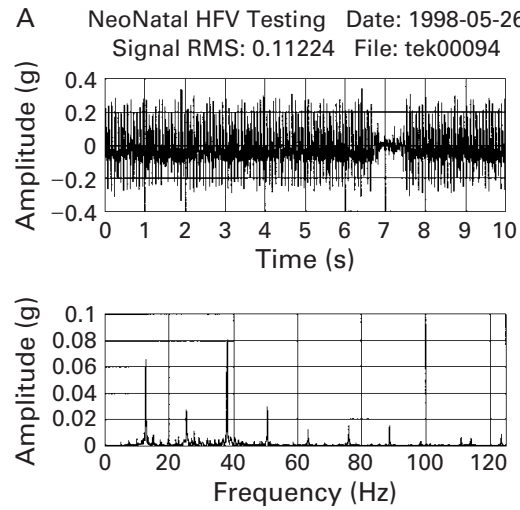

B

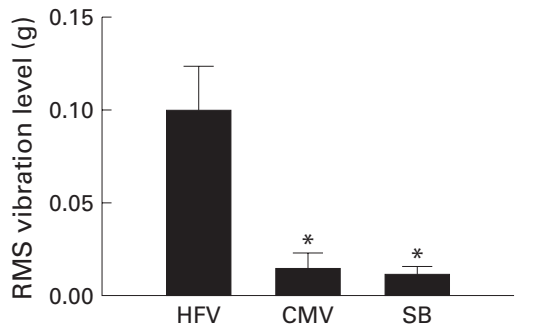

Figure 1 Vibration in neonates during high frequency ventilation $(H F V, n=7)$, conventional mechanical ventilation $(C M V, n=7)$, and spontaneous breathing $(S B, n=7)$. (A) Representative vibration signals at the mid sternum of a neonate during HFV (left) and CMV (right). The upper panel shows the recorded time signal while the bottom panel displays the same information transformed to the frequency domain to display the dominant frequencies present in the signal. (B) Vibration detected at the mid sternum (left panel) and postauricular cranium (right panel). ${ }^{*} p=0.001 v H F V(A N O V A)$.

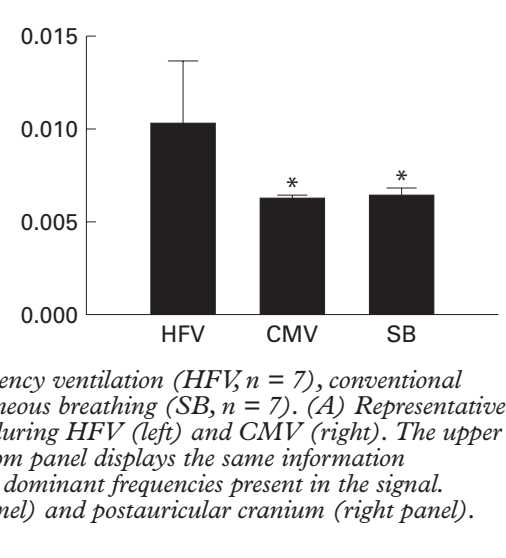

vibration in adults $(0.05 \mathrm{~g}$ at $12.5 \mathrm{~Hz}$ third octave band for 24 hours per ISO 2631).

The significance of our observations is not known. While cardiovascular instability is commonly observed in neonates during HFV and has been related to a high lung volume ventilation strategy, cardiovascular effects of vibration have been reported in animal ${ }^{2}$ and clinical studies. ${ }^{3}$ We speculate that the vibration during HFV may also contribute to the haemodynamic instability in neonates.
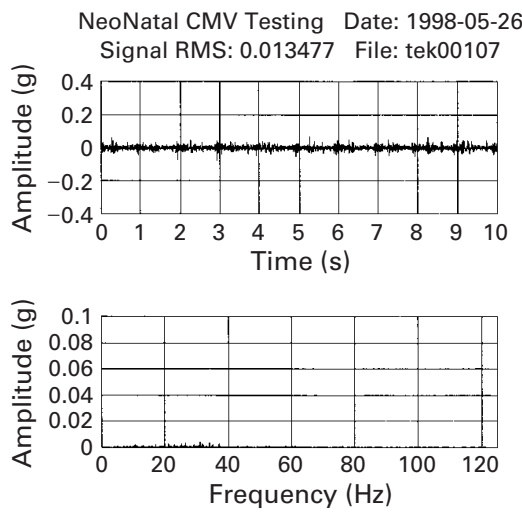
Furthermore, the effect of vibration on the developing brain is uncertain. We do not know whether the vibration will compromise the cerebral haemodynamic stability resulting in adverse neurological outcomes, especially in premature neonates who transmit vibration more efficaciously because of less body mass and fat compared with term neonates. Moreover, the combined effects of vibratory stress and environmental noise may contribute to hearing loss. ${ }^{4}$

Although no definitive vibration disease has been recognised in neonates, we have demonstrated the inadvertent exposure of neonates to excessive vibration. Research is required to examine the significance of HFV induced vibration and to reduce the vibration without compromising its effectiveness in critically ill neonates.

P-Y CHEUNG

Department of Newborn Medicine, Royal Alexandra Hospital, 10240 Kingsway Avenue, Edmonton, AB, Canada T5H $3 \mathrm{~V} 9$ poyin@ualberta.ca

P-Y CHEUNG ${ }^{\star}$ K FYFE $\dagger$ P C ETCHES C M T ROBERTSON * Departments of Pediatrics ${ }^{*}$ and Mechanical Engineeringt, University of Alberta, Edmonton,

Alberta, Canada

D B VICKAR

Department of Diagnostic Imaging, Royal Alexandra Hospital,

Edmonton,

Alberta, Canada

1 von Gierke HE, Brammer A. Effects of shock and vibration on humans. In: Harris CM, eds. The shock and vibration handbook. New York: McGraw-Hill, 1995: Chapter 44

2 Nakamura T, Hayashida Y. Cardiovascular responses to some stressors in conscious rats. Kurume Med f 1990; 37(Suppl):S117-22.

3 Matoba $T$, Itaya $M$, Toyomasu $K$, et al. Increased left ventricular function as an adaptive response in vibration disease. $A m \mathcal{F}$ Cardiol 1983; 51:1223-6.

4 Zhu S, Sakakibara H, Yamada S. Combined effects of hand-arm vibration and noise on temporary threshold shifts of hearing in he on subjects. Int Arch Occup Environ Health 1997; 69:433-6.

\section{National survey of detention and TB}

In England and Wales the power to detain individuals with tuberculosis who pose a threat to public health lies principally in sections 37 and 38 of the Public Health Act $1984 .{ }^{1}$ Section 37 authorises a local authority officer to remove an individual to a suitable hospital and section 38 authorises the "detention for a period specified in the order". By way of the Public Health (Infectious Diseases) Regulations 1988, in addition to the five notifiable diseases (cholera, plague, relapsing fever, smallpox, typhus), these sections currently apply to tuberculosis of the respiratory tract in an infectious state (although the term "infectious" is not defined by law).

Because central records are not kept, it has been unclear how many individuals are detained each year under legislation. ${ }^{2}$ No research has been conducted in Britain to determine trends in the use of detention as a public health tool in the control of tuberculosis, although a survey conducted in the early 1990 s of consultants in communicable disease control/medical officers of environmental health $(\mathrm{CCDC} / \mathrm{MOEH})$ reported the

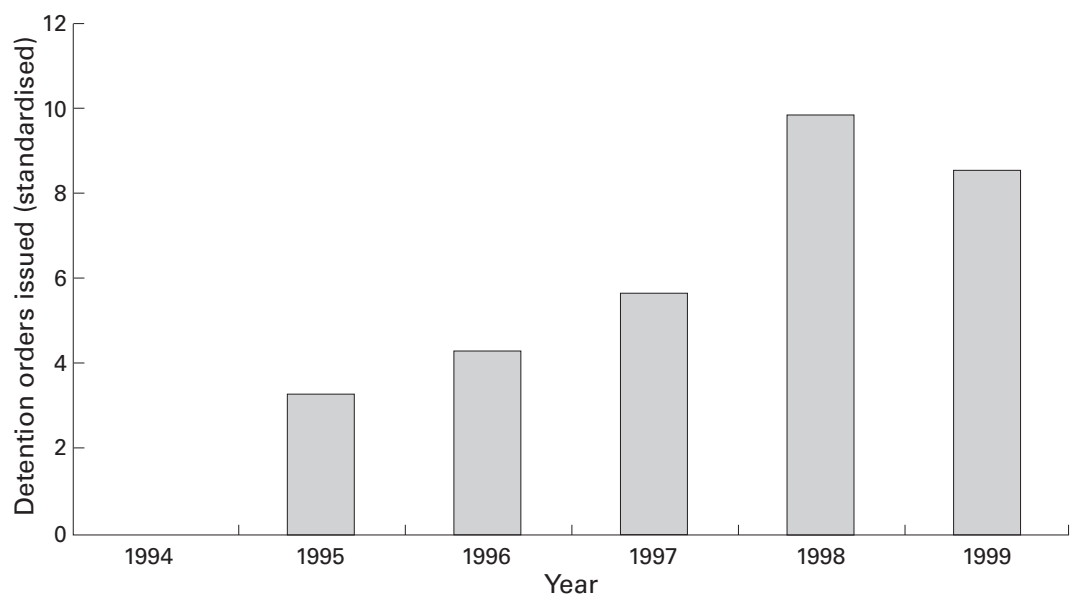

Figure 1 Section 38 detention orders controlled by pulmonary tuberculosis notification rate and health authority response rates in England and Wales, 1994-9.

issuance of six orders, "equivalent to less than one use of the sections for every hundred years of CCDC/MOEH experience".

A brief structured postal questionnaire was sent to consultants in communicable disease control in all 99 health authorities in England and Wales in February 2000 requesting information on whether any detention orders (section 38 of the 1984 Public Health Act) for individuals with tuberculosis had been issued in the health authority to which the letter had been sent since 1993. Information was received from consultants in 97 of the health authorities.

Thirty detention orders were issued during the 6 years surveyed; the year of issuance was given for 29. There was no apparent clustering in any health authority although 13 orders $(43 \%)$ were issued in London. The duration of the period of the detention orders varied from 3 days $(n=1)$ to 6 months $(n=6)$ with a median of 3 months.

The number of detention orders being issued for individuals with tuberculosis since 1994 has increased significantly $(\mathrm{p}<0.005)$. By $19990.2 \%$ of individuals notified with pulmonary tuberculosis were issued with detention orders. Regression analysis, taking account of health authority response rates and notification rates for pulmonary tuberculosis, shows a significant increase in the issuance of detention orders since 1994 $\left(b=1.8283, r^{2}=0.9\right.$; fig 1$)$.

The reasons for the increase in numbers of detention orders being issued are unclear. Increases in the incidence of tuberculosis outbreaks in healthcare settings and the scourge of drug resistant and multidrug resistant strains have, over the past decade, perhaps concentrated the minds of clinicians and public health physicians on ensuring that patients comply with treatment, and this may be playing a part. Elsewhere, notably in New York but also in Europe, consideration of the legal and ethical aspects of contemporary control measures has resulted in legislative amendments to public health laws which have enabled public health authorities to detain, for prolonged periods, patients with tuberculosis who will not or cannot comply with treatment. ${ }^{4-7}$ Failures in tuberculosis control allied to insufficient resources to facilitate patients' adherence to treatment, particularly in London, may also be contributing to the use of more restrictive measures by the authorities. ${ }^{89}$ An alternative explanation may be that, because of drug resistance and associated HIV infection, the treatment of tuberculosis is becoming increasingly complex, demanding greater commitment from patients and clinicians. This survey suggests that there is a need to monitor formally, in an ongoing fashion, trends in the issuance of detention orders for individuals with tuberculosis.

I thank the consultants in communicable disease control in England and Wales for assisting with this research and the Communicable Disease Surveillance Centre for providing the data on pulmonary tuberculosis notifications.

$$
\begin{array}{r}
\text { R J COKER } \\
\text { London School of Hygiene E Tropical Medicine, } \\
\text { ECOHOST, } \\
\text { London WC1E 7HT,UK } \\
\text { Richard.coker@lshtm.ac.uk }
\end{array}
$$

1 Coker RJ. The law, human rights, and the detention of individuals with tuberculosis in England and Wales. $f$ Public Health 2000;22:263-7.

2 Written answer 306 c447-8W. Hansard, 14 February 1998

3 Kaur B, Bingham P. Compulsory removal to and detention in hospital in the case of notifiable disease: a survey of public health doctors. Public Health 1993;107:199-204.

4 Coker RJ. From chaos to coercion: detention and the control of tuberculosis. New York: St Martin's Press, 2000.

5 Gasner MR, Maw KL, Feldman GE, et al. The use of legal action in New York City to ensure
treatment of tuberculosis. N Engl F Med 1998; 340:359-66.

6 Communicable Diseases Control Act, Norway, 1994.

7 Health Council of the Netherlands: Committee on Ethical and Legal Aspects of Tuberculosis Control. Compulsion and pressure in tuberculosis control. Publication no 1996/07. The Hague: Health Council of the Netherlands, 1996.

8 Hayward A. Tuberculosis control in London: the need for change. A report for the Thames Regional Directors of Public Health (discussion document). London: NHS Executive, 1998.

9 Hayward AC, Coker RJ. Could a tuberculosis epidemic occur in London as it did in New York? Emerg Infect Dis 2000;6:12-6.

\section{Churg-Strauss syndrome}

We read the review of Churg-Strauss syndrome (CSS) by Conron and Beynon ${ }^{1}$ with interest. The studies they quote are all reported from tertiary or national referral centres with inevitable referral bias. We have published our experience of 23 patients with $\mathrm{CSS}^{2}$ - the only study from a district general hospital which may be more representative of the natural history of this systemic vasculitis in 
the general population. The mean age of onset was 57 years, significantly older than the 40 years reported in patients from tertiary centres and quoted by Conron and Beynon. We found there was a slight male preponderance $(65 \%)$, also shown in many previous studies. The commonest sites of extrarespiratory involvement were, in descending frequency, the nervous system, joints and muscles, kidneys, skin, heart, and gastrointestinal tract. Involvement of the gastrointestinal tract occurred in only $30 \%$ and abdominal pain was uncommon. Cardiac involvement occurred in $44 \%$ and was the cause of death in two. Renal involvement, although occurring in nearly half the patients, was usually mild and none had severe renal failure.

The mean age of onset of asthma was 50 years and, although not reported, the asthma was not usually troublesome or severe when the systemic vasculitis developed. Indeed, very few patients were on oral steroids for their asthma at that time. Very rarely, patients present with CSS who do not have asthma. In our series there was one such patient who satisfied the original histological features of Churg and Strauss.

We found that the criteria developed by Lanham et $a l^{\beta}$ were the most useful, particularly an eosinophil count of $\geqslant 1.5 \times 10^{\circ} / 1$. While this is arbitrary, only one of our patients had a level below this and that was $1.4 \times 10^{9} / 1$.

B D W HARRISON D G I SCOTT Departments of Respiratory Medicine and Rheumatology Norfolk and Norwich University Hospital, Norwich, Norfolk NR1 3SR, UK brian.harrison@norfolk-norwich.thenhs.com

1 Conron M, Beynon HLC. Churg-Strauss syndrome. Thorax 2000;55:870-7.

2 Reid AJC, Harrison BDW, Watts RA, et al. Churg-Strauss syndrome in a district hospital. Qf Med 1998;91:219-29.

3 Lanham JG, Elkon KB, Pusey CD, et al. Lystemic vasculitis with asthma and Systemic vasculitis with asthma and Strauss syndrome. Medicine (Baltimore) 1984 63:65-81.

\section{Acute rib fracture pain in CF}

Recent papers in Thorax have described the high prevalence of low bone mineral density (BMD) in individuals with cystic fibrosis ${ }^{12}$; these patients are at increased risk of fractures. ${ }^{34}$ Rib fracture pain can often be difficult to treat, despite standard analgesia such as non-steroidal anti-inflammatory drugs and opiates. Rib pain can impair sputum clearance and lead to an exacerbation of CF pulmonary disease. There are reports that calcitonin can relieve bone pain for patients with osteolytic metastases ${ }^{5}$ and osteoporotic vertebral fractures. ${ }^{6}$ Recently, we have successfully used subcutaneous calcitonin for the treatment of rib fracture pain in two patients with CF.

A 25 year old woman fractured two ribs when she was crushed in the crowd at a rock concert and a 28 year old man fractured ribs following a bout of coughing. Both patients had CF related low BMD with DEXA Z scores at the lumbar spine of -2.5 and -3.6 , respectively. They had been taking long term oral prednisolone at a dose of $10 \mathrm{mg}$ per day Both patients had continuous uncontrolled pain from their fracture sites despite regular oral analgesics. The female patient was taking paracetamol $1 \mathrm{~g}$ qds and morphine sulphate modified release $30 \mathrm{mg}$ bd; the male patient was taking paracetamol $1 \mathrm{~g}$ qds and ibuprofen $600 \mathrm{mg}$ tds. Both patients were given courses of antibiotics as the pain was leading to an exacerbation of their CF lung disease. Subcutaneous calcitonin (salcatonin) was given in a dose of 50 units once daily. The pain completely resolved within 48 hours in both cases, and the patients were able to mobilise, perform sputum clearance, the other analgesics were withdrawn, and the chest exacerbations resolved. The calcitonin injections were continued for a total of 7 days, then stopped without recurrence of any pain. Neither patient experienced any side effects from the calcitonin.

Although calcitonin is involved in the regulation of bone turnover, the mechanism of its analgesic action is unknown. It reduces bone resorption and bone blood flow, but may also have central analgesic effects. Conversely, intravenous bisphosphonates, given to improve bone density, were associated with severe bone pain in individuals with $\mathrm{CF}^{7}$

Pain control is essential in patients with $\mathrm{CF}$ and rib fractures if adequate sputum clearance is to be achieved and an acute deterioration in lung disease avoided. Calcitonin should be considered as an analgesic in this situation. Such intervention may reduce morbidity and mortality associated with rib fractures in this group of patients.

A M JONES
M E DODD
A K WEBB
Adult Cystic Fibrosis Centre,
Wythenshawe Hospital,
Manchester M23 9LT,UK
andmarkj@hotmail.com
P L SELBY
Department of Medicine,
University of Manchester,
Manchester M13 $9 W L, U K$

1 Conway SP, Morton AM, Oldroyd B, et al. Osteoporosis and osteopenia in adults and adolescents with cystic fibrosis: prevalence and associated factors. Thorax 2000;55:798-804.

2 Haworth CS, Selby PL, Webb AK, et al. Low bone mineral density in adults with cystic bone mineral density in adult
fibrosis. Thorax 1999;54:961-7.

3 Henderson RC, Spencer BB. Kyphosis and fractures in children and young adults with fractures in children and young adults
cystic fibrosis. I Paediatr 1994;125:208-12.

4 Aris RM, Renner JB, Winders AD, et al. Aris RM, Renner JB, Winders $\mathrm{AD}$, et al.
Increased rate of fractures and severe kyphosis: Increased rate of fractures and severe kyphosis:
sequelae of living into adulthood with cystic sequelae of living into adulthood with cysic
fibrosis. Ann Intern Med 1988;128:186-93.

5 Szanto J, Ady N, Jozsef S. Pain killing with calcitonin nasal spray in patients with malignan tumours. Oncology 1992;49:180-2.

6 Lyritis GP, Tsakalakosn N, Magiasis B, et al. Analgesic effect of salmon calcitonin in osteoporotic vertebral fractures: a double-blind placebo-controlled clinical study. Calcif Tissue Int 1991;49:369-72.

7 Haworth CS, Selby PL, Webb AK, et al. Severe bone pain after intravenous pamidronate in adult patients with cystic fibrosis. Lancet 1998; 352:1753-4.

\section{Endothelin in acute exacerbations of COPD}

We read with interest the article by Roland et $a l^{1}$ on endothelin-1 (ET-1) levels in exacerbations of chronic obstructive pulmonary disease (COPD). The authors found increased sputum levels of ET-1 in patients with COPD during an exacerbation and this was reflected by a smaller rise in venous ET-1 levels.

We have recently performed a study to evaluate pulmonary and renal ET levels in nine consecutive COPD patients during an acute exacerbation. ${ }^{2}$ ET was detected by radioimmunoassay in venous and arterial blood as well as in a timed urine specimen. For each subject the ratio of systemic arterial/ mixed venous ET-1 levels (ir-ETart/ir-ETven) was evaluated as an index of pulmonary clearance/production of the peptide. ${ }^{3}$ The ir-ETart/ir-ETven ratio was comparable in patients with COPD examined both during an exacerbation and at recovery $(0.75(0.12)$ and 0.77 (0.13), respectively). Otherwise, the calculated ir-ETart/ir-ETven ratio in patients with COPD was significantly lower than that calculated in patients with acute pulmonary embolism, a condition in which pulmonary endothelial dysfunction is likely to occur. ${ }^{4} \mathrm{~A}$ significant difference was found with respect to 24 hour ir-ET urinary excretion between COPD patients during an exacerbation and at recovery (142.1 (12.8) $\mathrm{ng} / 24$ hours and 89.0 (15.1) ng/24 hours, respectively). Furthermore, renal clearance of ET was higher in COPD patients during an exacerbation $(29.2$ (5.2) $\mathrm{ml} / \mathrm{min})$ than at recovery $(17.5(3.9) \mathrm{ml} /$ min), suggesting an increase in renal ET production in patients with COPD during an exacerbation in the absence of significant changes in ET-1 circulating levels.

We therefore think that increased sputum ET-1 levels found in patients with COPD during an acute exacerbation could represent a true increase in local ET production, although a firm relationship between venous and sputum ET-1 levels could not be established.

Correspondence to: M Maniscalco

M SOFIA
M MANISCALCO
Pulmonary and Airway Vascular Unit,
AO Monaldi, University "Federico II"
Napoli,
Italy

1 Rolan M, Bhowmik A, Sapsford RJ, et al. Sputum and plasma endothelin-1 levels in exacerbations of chronic obstructive pulmonary disease. Thorax 2001;56:30-5.

2 Sofia M, Maniscalco M, Celentano L, et al. Abnormalities of renal endothelin during acute exacerbation in chronic obstructive pulmonary disease. Pulm Pharmacol Ther 2001;14:321-7.

3 Druml W, Streltzer H, Waldhavse W, et al. Endothelin-1 in adult respiratory distress syndrome. Am Rev Respir Dis 1993;148:116973.

4 Sofia M, Faraone S, Alifano M, et al. Endothelin abnormalities in patients with pulmonary embolism. Chest 1997;11:544-9.

\section{CF and antistaphylococcal prophylaxis}

Dr Robinson's review of cystic fibrosis (CF) touches on the use of continuous antistaphylococcal antibiotic prophylaxis. ${ }^{1} \mathrm{Dr}$ Robinson reiterates the oft repeated assertion that there is an association between the use of prophylactic antibiotics and the early acquisition of pulmonary infection with Pseudomonas aeruginosa in patients with CF. This putative association has entered CF folklore but is not supported by any published evidence. The paper cited by Robinson describes a pilot study of cephalexin which lasted 2 months. ${ }^{2} \mathrm{~A}$ subsequent multicentre randomised placebo controlled trial of cephalexin, commenced in children under 2 years, has been undertaken and its methodology described. ${ }^{3}$ However, no results have so far appeared in the published literature.

We have recently published an updated systematic review of randomised controlled trials of prophylactic antibiotics in CF. ${ }^{4}$ This describes data from three studies involving 185 children. We found that fewer children 
who received prophylaxis from birth had one or more isolates of Staphylococcus aureus over a 3 year period. There was also evidence at 2 years that less time was spent in hospital in the prophylaxis group. The number of children receiving prophylaxis who had one or more isolates of $P$ aeruginosa over a 3 year period was half that of the control group who had intermittent antibiotic treatment only. This was not, however, statistically significant (Peto odds ratio $0.54,95 \%$ confidence interval 0.23 to 1.26 ).

The steering group of the North American cephalexin trial have indicated that its results will be published soon (Eliezer Nussbaum, personal communication). However, until there is published evidence from at least one properly designed randomised controlled trial, the proposal that prophylaxis encourages pulmonary infection with $P$ aeruginosa remains entirely speculative.

A SMYTH

Department of Paediatrics, Nottingham City Hospital, Nottingham NG5 1PB, UK DrAlanSmyth@compuserve.com $S$ WALTERS

Department of Public Health and Epidemiology, University of Birmingham, University of Birmingham,
Birmingham B15 2TT, UK s.walters@bham.ac.uk

1 Robinson P. Paediatric origins of adult lung disease. 7: Cystic fibrosis. Thorax 2001;56:23741.

2 Harrison CJ, Marks MI, Welch DF, et al. A multicentric comparison of related pharmacologic features of cephalexin and dicloxacillin given for two of cephalexin and dicloxacillin given for two months to young children with 3 Stutman HR, Marks MI. Cephalexin prophylaxis in newly diagnosed infants with cystic fibrosis. 6th North American Cystic Fibrosis Conference 1992: 147-8 (abstract).

4 Smyth A, Walters S. Prophylactic antibiotics for cystic fibrosis (Cochrane Review). In: The Cochrane Library, Issue 3. Oxford: Update Software, 2001.

AUTHOR'S REPLY I thank Drs Smyth and Walters for their comments concerning the issue of whether antistaphylococcal prophylaxis leads to a higher risk of colonisation with Pseudomonas aeruginosa in patients with cystic fibrosis. I share their concern as to the lack of definitive data supporting this notion and, indeed, tried to illustrate this in my article by stating "There is some evidence that it may be associated . ..". ${ }^{1}$ I would suggest, however, that the authors' evidence of a lack of association is equally thin - to quote a multicentre trial whose methodology was presented as an abstract some 9 years ago but whose results do not appear to have ever been published in a peer reviewed journal is certainly not basing one's evidence on hard evidence based facts. I did not mention the review by Smyth and Walters ${ }^{2}$ in my own paper as I submitted my review some 18 months before theirs had been published; however, the authors did not include in their own letter discussion of the recent paper by Ratjen $e t a l^{3}$ using data from the German CF database which included 639 patients, all under 18 years of age and $P$ aeruginosa negative prior to entry in the study. $48.2 \%$ of the patients received continuous antistaphylococcal treatment, $40.4 \%$ received intermittent antibiotic treatment, and $11.4 \%$ received no antibiotic treatment. While the rate at which patients acquired positive respiratory cultures for Staphylococcus aureus was significantly lower in the group receiving continuous antistaphyloccocal antibiotic treatment than in those receiving no such treatment, patients receiving continuous antistaphyloccocal antibiotic treatment had a significantly higher rate of $P$ aeruginosa acquisition than patients receiving only intermittent or no antibiotic treatment. This difference was especially apparent for children under the age of 6 years. The authors concluded that "continuous therapy with antistaphyloccocal antibiotics directed against Staph aureus increases the risk of colonisation with $P$ aeruginosa".

This interesting study I believe again supports my original statement that "there is some evidence that it (continuous antistaphyloccocal antibiotic therapy) may be associated with earlier acquisition of $P$ aeruginosa".

P ROBINSON Cystic Fibrosis Unit, Department of Respiratory Medicine, Royal Children's Hospital, Melbourne Australia 3052 philrob@cryptic.rch.unimelb.edu.au

1 Robinson P. Pediatric origins of adult lung disease. 7: Cystic fibrosis. Thorax 2001; 56: 237-41.

2 Smyth A, Walters S. Prophylactic antibiotics for cystic fibrosis (Cochrane Review). In: The Cochrane Library, Issue 2. Oxford: Update Software, 2001.

3 Ratjen F, Comes G, Paul K, et al. Continuous antistaphylococcal therapy on the rate of $P$ aeruginosa acquisition in patients with cystic fibrosis. Pediatr Pulmonol 2001;31:13-6.

\section{NOTICES}

\section{The Dr H M (Bill) Foreman Memorial} Fund

The Trustees of the above fund invite applications for grants relating to study in respiratory disease and allied fields. Limited funds are available for registered medical practitioners to assist in travelling to countries other than their own to study respiratory disease, and also for support for clinical research abroad
The HMF Fund has been able to fund two medical student projects in the last 18 months, one on TB in Malaysia and one on TB in Ghana, and has awarded three travel grants to study the following aspects of respiratory disease: Dr Veronica White (London) to study TB in Bangladesh; Dr R T Jagoe (Newcastle upon Tyne) to study the ATPubiquitin-proteasome proteolytic system in Boston, USA; Dr J S Parmar (Cambridge) to study cell motility in Toronto; and a grant to Dr Anne Chang (Brisbane) to study the relationship between cough and asthma.

Intending applicants should write for further details to Dr Brian H Davies, Llandough Hospital, Penarth, Vale of Glamorgan CF64 2AA, UK.

\section{Pharmacology of Asthma}

A course on the "Pharmacology of Asthma" organised by Professor Peter Barnes will be held at the Imperial College School of Medicine at the National Heart \& Lung Institute in collaboration with the Royal Brompton Hospital, Dovehouse Street, London SW3 6LY, UK on 26-29 November 2001. The course is suitable for physicians or scientists with an interest in the pharmacology and therapeutics of asthma. For further information please contact the Postgraduate Education Centre, Imperial College School of Medicine at the National Heart \& Lung Institute, Dovehouse Street, London SW3 6LY. Telephone: 0207351 8172. Fax: 0207351 8246. Email: shortcourses.nhli@, ic.ac.uk

\section{Respiratory Medicine}

A conference on Respiratory Medicine will be held at the Royal College of Physicians of Edinburgh on 26 October 2001. For further information contact Ms Eileen Strawn, Symposium Coordinator. Telephone 0131225 7324. Fax 0131220 4393. Email: e.strawn@ rcpe.ac.uk. Website: www.rcpe.ac.uk.

\section{CORRECTION}

In the "Statement on Malignant Mesothelioma in the United Kingdom" by the British Thoracic Society Standards of Care Committee which appeared in the April issue of Thorax (2001;56:250-65), the telephone number given for the National Mesothelioma Helpline on page 264 is incorrect. The correct number is 0113206 6466. The email address is mavisro@ulth.northy.nhs.uk 